\title{
TENSILE PROPERTIES OF COMMERCIALLY PURE VANADIUM \\ FROM ROOM TEMPERATURE TO $1200^{\circ} \mathrm{C}$
}

\author{
G. A. Henshall \\ S. G. Torres
}

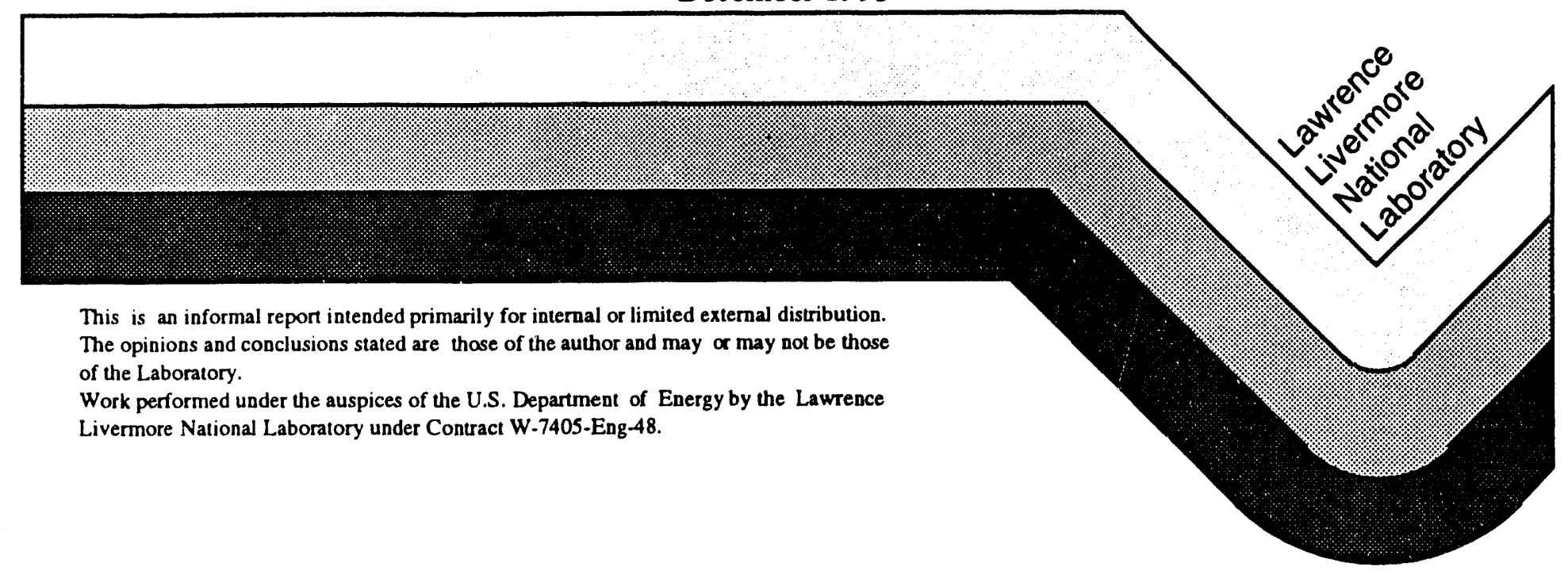




\section{DISCLAIMER}

This document was prepared as an account of work sponsored by an agency of the United States Government. Neither the United States Government nor the University of California nor any of their employees, makes any warranty, express or implied, or assumes any legal liability or responsibility for the accuracy, completeness, or usefulness of any information, apparatus, product, or process disclosed, or represents that its use would not infringe privately owned rights. Reference herein to any specific commercial products, process, or service by trade name, trademark, manufacturer, or otherwise, does nol necessarily constitute or imply its endorsement, recommendation, or favoring by the United States Government or the University of California. The views and opinions of authors expressed herein do not necessarily state or reflect those of the United States Government or the University of California, and shall not be used for advertising or product endorsement purposes.

This report has been reproduced directly from the best available copy.

Available to DOE and DOE contractors from the Orice of Scientific and Technical Information

P.O. Box 62, Oak Ridge, TN 37831

Prices available from (615) 576-8401, FTS 626-8401

Available to the public from the

National Technical Information Service

US. Department of Commerce

S285 Port Royal Rd,

Springfield, VA 22161 


\title{
Tensile Properties of Commercially Pure Vanadium from Room Temperature to $1200{ }^{\circ} \mathrm{C}$
}

\author{
G. A. Henshall and S. G. Torres
}

Abstract - The tensile properties of vanadium are extremely sensitive to interstitial impurity content and, to some extent, on grain size and strain rate. Therefore, for purposes of design and finite-element structural analyses, it is problematic to use published tensile data for materials potentially varying in these quantities. This investigation was undertaken to fuliy characterize the tensile properties of the commercially pure vanadium used at Lawrence Livermore National Laboratory. Both sheet and rod stock were tested in vacuum from ambient temperature to $1200^{\circ} \mathrm{C}$ at strain rates ranging from $6.67 \times 10^{-5}$ to $6.67 \times 10^{-2} \varsigma^{-1}$.

The results of these experiments show that vanadium behaves in a manner typical of many bcc metals containing interstitial impurities. Local peaks in the yield stress and ultimate tensile stress vs. temperature curves are observed at intermediate temperatures. Serrated yielding also is obseived in some temperature ranges. Changes in strain rate within the quasi-static regime were found to have a relatively small and predictable effect on the mechanica' response. The rod and sheet stock have similar properties, except that the lower yield stress of the rod is less than that of the sheet over most of the temperature range studied. In addition, no plateau in the yicld strength vs. temperature curve was observed for the rod. In both forms, and for all temperatures, vanadium is ductile. The elongation to failure reaches a minimum of approximately $35 \%$ at a temperature of 500 ${ }^{\circ} \mathrm{C}$ and a maximum of approximately $140 \%$ at $1200^{\circ} \mathrm{C}$. 


\section{Introduction}

Vanadium is a body-centered-cubic (bcc) refractory metal that finds a number of uses in the nuclear weapons and energy industries, either in pure form or alloyed. While a number of previous studies have reported on the tensile properties of vanadium [1-5], a review of this literature [6] showed that there is a large amount of scatter in the data, Fig. 1. Scatter in these data may be due in part to differences (not always documented) in specimen geometry, strain rate, and grain size. Largely, however, the differences in properties are due to differences in impurity content, especially interstitial oxygen, nitrogen, carbon, and hydrogen. As with other bcc metals, such as iron, interstitial atoms interact strongly with dislocations and greatly influence mechanical behavior. The scatter in the data depicted in Fig. 1 results in a large uncertainty in the tensile properties. This level of uncertainty is unacceptable to the designer or finite element analyst performing structural calculations involving vanadium.

The purpose of the investigation described here was to establish the tensile properties of the commercially pure vanadium specifically used by Lawrence Livermore National Laboratory (LLNL). Since both rod and sheet stock are employed at LLNL, both of these forms were investigated. These materials were tested over a wide range of temperatures and at several quasi-static strain rates to fully document the tensile properties over the range of conditions to which the material may be exposed during service (with the exception of high strain rates). These data are presented in a form that should be of benefit to designers and finite element analysts at LLNL (see the Appendix). This investigation also represents an extension of a previous LLNL study by dePruneda, Gallegos and Stratman [7], and our data are compared with these earlier results. 


\section{Experimental Materials and Procedures}

The material used for testing was commercially pure vanadium synthesized by the Teledyne Wah Chang Co. Stock material consisted of electron-beam melted, crossrolled and annealed 1/8-inch thick sheet (specification no. RM254921), and electronbeam melted 1/2-inch diameter bar (specification no. RM255525). The interstitial contents, as measured by LECO instrumentation, are listed in Table 1. Impurity contents are given for the as-received sheet, a sheet specimen following testing at $500{ }^{\circ} \mathrm{C}$, and for the as-received rod. Initial microstructures consisted of a single phase with an equiaxed grain structure for both forms of stock. For the rod, the initial grain size was ASTM 7, or an average grain diameter, $d=28.2 \mu \mathrm{m}$. As shown in Fig. 2, the grain size of the sheet varied through its thickness from ASTM $8(d=19.9 \mu \mathrm{m})$ to ASTM $6(d=39.9 \mu \mathrm{m})$. The presence of a variable grain size through the thickness of vanadium sheet appears to be common from our observations of several sheets and as observed by Glenn et al. [8]. Since the major goal of this investigation was to document the properties of the material used at LLNL, rather than to perform a fundamental study, no effort was made to homogenize the grain structure.

Table 1. Interstitial impurity contents for commercially pure vanadium (ppm by weight).

\begin{tabular}{|c|c|c|c|c||c|}
\hline Material & Oxygen & Nitrogen & Carbon & Hydrogen & Total \\
\hline Sheet As received & 240 & 60 & 110 & 3 & 413 \\
\hline SheetPost-test & 370 & 70 & 110 & 3 & 553 \\
\hline Rod & 200 & 60 & 50 & 2 & 312 \\
\hline
\end{tabular}


Sheet specimens were machined to the dimensions given in Fig. 3, with a 12.7$\mathrm{mm}(0.5$-in.) gage length. The rod was machined into specimens with the geometry shown in Fig. 4. The gage section of the rod specimens was $12.7 \mathrm{~mm}(0.5 \mathrm{in}$.) long with a diameter of $6.35 \mathrm{~mm}\left(0.25 \mathrm{in}\right.$.). All specimens were vacuum annealed at $900^{\circ} \mathrm{C}$ for one hour prior to testing. Annealing was performed between Ta foil sheets to getter impurities. The grain size was not affected by the anneal.

Tensile testing was performed in vacuum (approx. $5 \times 10^{-6}$ torr) at temperatures from ambient to $1200^{\circ} \mathrm{C}$ using a "Brew" vacuum furnace. This furnace was mounted on a screw-driven Instron Model TT-D-L universal testing machine. TZM molybdenum was used for grips and tensile linkages, with universal joints employed to ensure alignment. Two type S thermocouples (Pt-Pt 10\% Rh) were held in contact with the specimens at opposite ends of the gage section to measure specimen temperatures and temperature gradients. These gradients were typically $\pm{ }^{\circ} 2 \mathrm{C}$ along the gage section but occasionally reached values as high as $\pm 5^{\circ} \mathrm{C}$. Tests were performed at crosshead speeds of 0.002 to $2.0 \mathrm{in} . / \mathrm{min}$., corresponding to engineering strain rates of $6.67 \times 10^{-5}$ to $6.67 \times 10^{-2} \mathrm{~s}^{-1}$. Load vs. time data were collected using an HP-3497A data acquisition system with an HP-9816 computer. Engineering strains were computed from the known crosshead speeds and the elapsed time of the test. This method for measuring strain, although approximate, was found to be adequate because of the high ductility of the vanadium. Greater detail concerning the experimental methods employed in this study are available elsewhere [9]. 


\section{Experimental Results}

\section{Sheet Material}

\section{Properties at the base strain rate}

The variation in the yield stress with temperature for commercially pure vanadium sheet at the "base" strain rate of $6.67 \times 10^{-4} \mathrm{~s}^{-1}$ is given in Figure 5. For many of the test temperatures, a yield point, or yield drop [10], was observed. For these tests, both the upper yield strength (UYS) and lower yield strength (LYS) are reported in the figure. In the classic case of steels, the cause of the yield point phenomenon is the interaction of interstitial solutes with dislocations [10-12]. This explanation has been confirmed for vanadium, as well $[6,7]$. At temperatures above $900^{\circ} \mathrm{C}$ a yield point was not observed, so the $0.2 \%$-offset yield strength is reported in Fig. 5 .

The scatter in the LYS and $0.2 \%$-offset yield strength data is only a few percent, but the scatter in the UYS data is significantly larger. The scatter is greatest in the temperature range $450-600^{\circ} \mathrm{C}$. In this regime, the UYS is very sensitive to changes in temperature so that small temperature gradients along the specimen length during testing have a magnified effect on the measured response. Slight misalignment of the specimen with tensile axis also will influence the UYS much more than the LYS or the $0.2 \%$-offset yield stress.

Consistent with many other bcc metals, there is a "plateau" in the yield strength vs. temperature curve at intermediate temperatures, in this case $200-700{ }^{\circ} \mathrm{C}$. Again, this behavior is associated with the interaction between dislocations and solutes, particularly interstitials [12-14]. At temperatures either above or below the plateau, the yield strength decreases rapidly with increasing temperature.

Figure 6 presents the variation in ultimate tensile stress (UTS) with temperature for the base strain rate. The UTS decreases with increasing temperature from room 
temperature (and probably below) up to about $200^{\circ} \mathrm{C}$. A sharp peak in the UTS then is observed at about $500^{\circ} \mathrm{C}$. Above this peak, the UTS decreases rapidly with increasing temperature. The peak in the UTS vs. temperature curve at intermediate temperatures is almost certainly caused by the synergistic effects of work hardening and solute strengthening that have been observed in other alloys [11-14]. There also appears to be a slight perturbation in the UTS vs. temperature curve in the temperature range of $800-1000$ ${ }^{\circ} \mathrm{C}$. Although not confirmed, this perturbation may be the result of interactions between dislocations and less mobile substitutional imipurities. Serrations in the stress-strain curve were observed in this temperature regime, just as for temperatures near the UTS peak at $500{ }^{\circ} \mathrm{C}$. Serrated yielding is often associated with peaks in the stress-temperature response and has been attributed to dislocation-solute interactions [14].

The dependence of the nominal failure strain, or elongation to failure, on temperature is shown in Fig. 7 for the base strain rate. Commercially pure vanadium is a ductile metal at all temperatures tested. From ambient temperature to about $800^{\circ} \mathrm{C}$ the elongation to failure ranges from about $35 \%$ to $65 \%$. For the temperatures of $400-500{ }^{\circ} \mathrm{C}$ there is a slight decrease in the elongation, consistent with the inverse temperature sensitivity and (as shown later) the negative strain rate sensitivity of the flow stress. A negative strain rate sensitivity has been correlated with minima in ductility for many materials $[14,15]$. From 600 to about $700{ }^{\circ} \mathrm{C}$, the ductility increases with increasing temperature. This behavior is consistent with the rapid decrease in UTS over this range, implying that the strain-rate sensitivity is large and positive, promoting ductility. A sharp minimum in the ductility is then observed at $900{ }^{\circ} \mathrm{C}$. The cause of this minimum is not known for certain, but it is coincident with the perturbation in UTS described earlier. Again, this points to the possibility that low mobility impurities are causing an increase in strength and a decrease in ductility in this temperature range. The presence of serrations in the stress-strain curve and a slight yield point at 800 and $900^{\circ} \mathrm{C}$ are consistent with this 
hypothesis. At temperatures above $900^{\circ} \mathrm{C}$, the elongation rapidly rises as the temperature increases, with an elongation of about $140 \%$ observed at $1200^{\circ} \mathrm{C}$.

Grain growth during testing at the base strain rate was not observed at temperatures of $1100^{\circ} \mathrm{C}$ or below. At $1200^{\circ} \mathrm{C}$, however, grain growth was extensive. Following testing, the grain size in the grip section of this specimen was ASTM 2 ( $d=$ $180 \mu \mathrm{m})$. The in-situ grain growth may affect the tensile properties of the material in a way that is not easily quantified. For the purposes of this investigation, however, it is not particularly important to separate the effects of grain growth at high temperatures from the intrinsic properties of the material since grain growth will be inevitable at these temperatures and will always influence the mechanical behavior.

\section{Effects of strain rate}

A limited investigation of the effects of strain rate on the mechanical properties of vanadium was performed. At room temperature, testing was performed at three engineering strain rates: the base rate of $6.67 \times 10^{-4} \mathrm{~s}^{-1}$ and at rates of $6.67 \times 10^{-5} \mathrm{~s}^{-1}$ and $6.67 \times 10^{-2} \mathrm{~s}^{-1}$. Figure 8 shows the variation in the lower yield strength (LYS), upper yield strength (UYS), and ultimate tensile strength (UTS) with strain rate at room temperature. The LYS increases by about $30 \%$ as the strain rate increases from $6.67 \mathrm{x}$ $10^{-5}$ to $6.67 \times 10^{-2} \mathrm{~s}^{-1}$, while the UTS increases by about $15 \%$ over the same strain-rate range. The increase in strength with increasing strain rate is consistent with the increase in strength with decreasing temperature that occurs near room temperature. The room temperature elongation to failure as a function of strain rate is shown in Figure 9. Strain rate does not appear to significantly affect the room temperature ductility of vanadium over the range tested.

Based on the LYS data, the constant structure strain-rate sensitivity, $m$, was computed using [10]: 


$$
m=\left(\frac{\partial \log \sigma}{\partial \log \dot{\varepsilon}}\right)_{T, \varepsilon}
$$

where $\sigma$ is the stress, $\dot{\varepsilon}$ is the strain rate, $T$ is temperature and $\varepsilon$ is strain. The $\log$ (LYS) vs. $\log (\dot{\varepsilon})$ data are plotted in Fig. 10, and reveal a strain-rate sensitivity of about 0.04 . This value is typical of many metals at low temperatures $[9,10]$.

In addition to these room temperature tests, experiments were performed over the full range of temperature for the engineering strain rate of $6.67 \times 10^{-2} \mathrm{~s}^{-1}$. As shown in Fig. 11, the increase in strain rate produces a slight shift in the yield stress vs. temperature curve to higher temperatures, as expected. This is particularly noticeable at temperatures below $500^{\circ} \mathrm{C}$. In addition, the plateau in the yield stress is not as pronounced at the higher strain rate.

Figure 12 presents a comparison of the ultimate tensile stresses for the two strain rates. Again, a shift of the curve to higher temperatures at the higher strain rate is exhibited. This shift appears to be approximately $50-75^{\circ} \mathrm{C}$ over most of the temperature range. Note the negative strain-rate sensitivity of the UTS for temperatures of $400-500$ ${ }^{\circ} \mathrm{C}$; i.e. the UTS decreases as $\dot{\varepsilon}$ increases. This behavior is expected over a limited temperature range in the regime for which strength increases with increasing temperature at a constant strain rate [14]. Also, note that there is not a sharp peak in the UTS at intermediate temperatures for the high strain rate. This is believed to be an artifact of the data. Since the UTS is extremely sensitive to temperature near the peak, the temperature must be accurately controlled over the entire gage length for the entire test. Given the temperature gradients present in the vacuum furnace, this is difficult to achieve in practice, especially at the UTS where the elongation is significant. It is likely that a peak in the UTS of about $300 \mathrm{MPa}$ actually occurs at approximately $550{ }^{\circ} \mathrm{C}$ for the high strain rate. 
The variation in the elongation to failure as a function of temperature and strain rate is given in Fig. 13. The increase in strain rate by 2 orders of magnitude has little effect on the elongation to failure for most of the temperatures studied. The local minimum in elongation to failure appears to occur at about $550^{\circ} \mathrm{C}$ for the higher strain rate, which is approximately $50^{\circ} \mathrm{C}$ higher than that for the base strain rate. Also note that this local ductility minimum is coincident with the negative strain-rate sensitivity of the UTS in this temperature range.

\section{Rod Material}

The rod stock was tested only at the base strain rate of $6.67 \times 10^{-4} \mathrm{~s}^{-1}$. Figure 14 compares the lower or $0.2 \%$-offset yield strengths as a function of temperature for the rod and the sheet. Except at very high temperature, the yield strength of the rod is lower than that of the sheet. In addition, the rod does not exhibit the plateau in yield stress that was observed for sheet material. The reason for these differences in behavior probably is due to the differences in interstitial impurity contents. Examination of Table 1 shows that in the as-received condition the oxygen and carbon levels for the rod are lower than those for the sheet. In addition, Table 1 indicates that the sheet specimens pick up oxygen during annealing and testing. Since the surface-to-volume ratio of the rod specimens is much lower than that for the sheet (see Figs. 3 and 4) oxygen pick-up during annealing and testing probably is much lower than for the sheet. Thus, the level of interstitial impurities during testing appears to be significantly lower for the rod, leading to the behavior shown in Fig. 14. Another contribution to the disparity in yield strengths shown in Fig. 14 may be variations in grain size. As shown in Fig. 2, the sheet contains a large fraction of small $(d=20 \mu \mathrm{m})$ grains whereas the grains in the rod are uniform with $d=$ $28.2 \mu \mathrm{m}$. The regions of small grains most likely cause a slightly higher yield strength in the sheet compared with the rod [2]. Full exploration of these issues was beyond the scope of this investigation. 
Figure 15 presents the variation in the UTS with temperature for both the rod and the sheet. In this case, the two materials show essentially identical properties. Apparently, there is a large enough interstitial content in the rod to interact synergistically with the dislocations produced by strain hardening, causing a sharp peak in the UTS. The presence of large peaks in the stress vs. temperature curve at large strains when peaks are small or absent at small strains (e.g. at yield) has been observed in other materials $[11,13,14]$.

The dependence of the elongation to failure on temperature for the rod is compared to that of the sheet in Fig. 16. At temperatures from 23 to $700{ }^{\circ} \mathrm{C}$, the behavior of the two types of stock is similar, with the elongation to failure for the rod being somewhat higher than that of the sheet. The difference in specimen geometry probably accounts for the higher measured ductility for the rod. The rod specimens have a short gage length compared to their diameter. The length-to-width ratio for the sheet is larger, producing smaller elongations to failure [16]. At $900{ }^{\circ} \mathrm{C}$ the sheet material shows a minimum in the ductility. As discussed earlier, this may be due to low mobility impurities in the sheet. Apparently these impurities are absent in the rod since the ductility smoothly increases with increasing temperature above $700^{\circ} \mathrm{C}$ for this material. Finally, the rod shows substantially less ductility at $1200{ }^{\circ} \mathrm{C}$ than the sheet. The reason for this discrepancy is not known for certain, but may be associated with the difficulty in maintaining a small temperature gradient along the rod for the large elongation exhibited.

Examination of the microstructure in the grip of the rod specimen following the $1200^{\circ} \mathrm{C}$ tests showed that the grain size had increased to ASTM $4(d=80 \mu \mathrm{m})$. This increase is somewhat less than that observed in the sheet, for which the grains grew to ASTM 2, or $d=180 \mu \mathrm{m}$. This disparity may be associated with the lower ductility for the rod, which results in less time being spent at temperature. 


\section{Discussion}

The data of the present investigation compare well with the earlier results of dePruneda et al. [7] in the temperature range for which they conducted tests, $20-500^{\circ} \mathrm{C}$. For example, the UTS data of dePruneda et al. are plotted with the data of the present investigation $\left(6.67 \times 10^{-4} \mathrm{~s}^{-1}\right)$ in Fig. 17. Both the absolute magnitudes and trends in the data are similar for both studies, though the temperature at which the peak in the UTS occurs was measured to be somewhat higher in the present investigation. Differences in strain rate may account for this difference.

Comparing the data of the present study with those compiled by Gold et al. [6] (Fig. 1) reveals the usefulness of the present work. Relying on an "average" set of values for the YS or UTS from Fig. 1 would result in large deviations from the actual values for LLNL material in the $20-700{ }^{\circ} \mathrm{C}$ temperature range. For example, using the data compiled by Gold et al., an average UTS value at $400{ }^{\circ} \mathrm{C}$ would be approximately 50-60 ksi or $345-415 \mathrm{MPa}$. The value for LLNL material measured in the current study is about $33 \mathrm{ksi}$ or $230 \mathrm{MPa}$. The deviation between these values is $50-80 \%$. At temperatures above $800^{\circ} \mathrm{C}$, the data of the present investigation are similar to those presented by Gold et al., emphasizing the role of interstitial solutes in affecting the mechanical properties of vanadium, which is lost at high temperatures.

\section{Summary and Conclusions}

The tensile properties of the commercially pure vanadium commonly employed at Lawrence Livermore National Laboratory (LLNL) have been investigated over the temperature range of $20-1200^{\circ} \mathrm{C}$. Both $1 / 8$-inch thick sheet and 1/2-inch diameter rod stock were investigated. The results of this study show that vanadium behaves in a manner typical of a bcc metal containing interstitial impurities. Local peaks in the yield stress, and ultimate tensile stress vs. temperature curves are observed at intermediate temperatures. Serrated yielding also is observed in some temperature ranges. Changes in 
strain rate within the quasi-static regime were found to have a relatively small and predictable effect on the mechanical response. The rod and sheet stock have similar properties, except that the lower yield strength of the rod stock is less than that of the sheet over most of the temperature range studied. In addition, no yield strength plateau was observed for the rod. In both forms, and for all temperatures, vanadium is ductile. The elongation to failure reaches a minimum of approximately $35 \%$ at a temperature of $500^{\circ} \mathrm{C}$ and a maximum of approximately $140 \%$ at $1200^{\circ} \mathrm{C}$.

The results of this study supplement those of an earlier LLNL study, extending the data to higher temperatures and providing a preliminary evaluation of the effects of changes in strain rate. It has been shown that simply using "average" tensile properties taken from the literature to estimate the behavior of the commercially pure vanadium used at LLNL can lead to large errors.

\section{Acknowledgments}

The authors wish to acknowledge the financial support and technical guidance provided by Dr. James Hanafee and metallography by Bob Kershaw. 


\section{References}

1. J. W. Farrell, "Mechanical Properties of Unalloyed Vanadium," Trans. ASM 54, 143157 (1961).

2. T. C. Lindley and R. E. Smallman, "The Plastic Deformation of Polycrystalline Vanadium at Low Temperatures," Acta Metall. 11, 361-371 (1963).

3. W. R. Clough and A. S. Pavlovic, "The Flow, Fracture, and Twinning of Commercially Pure Vanadium," Trans. ASM 52, 948-970 (1960).

4. B. A. Loomis and O. N. Carlson, "Investigation of the Brittle-Ductile Transition in Vanadium," Reactive Metals, Vol. 2, The Metallurgical Society, Buffalo, NY, pp. $227-$ 243 (1958).

5. W. Rostoker, A. S. Yamamoto, and R. E. Riley, "The Mechanical Properties of Vanadium-Base Alloys," Trans. ASM 48, 560-578 (1956).

6. R. E. Gold, D. L. Harrod, R. L. Ammon, R. W. Buckman, and R. C. Svedberg, "Technical Assessment of Vanadium-Base Alloys for Fusion Reactor Applications: Final Report, Vol. 2," Westinghouse Electric Corp. Report No. COO-4540-1 (1978).

7. J. H. dePruneda, G. F. Gallegos, and M. P. Stratman, "The Effects of Furnace Environment on the Mechanical Properties of Vanadium," University of California Lawrence Livermore National Laboratory Report No. UCID-20726 (1988).

8. T. G. Glenn, G. W. Elliston, C. M. Edstron, and W. L. Johns, "Effect of Chemistry Variations on the Weldability of Commercially Pure Vanadium Sheet," Rockwell International Report No. RFP-3217 (1982).

9. S. G. Torres and G. A. Henshall, "Tensile Properties of 21-6-9 Stainless Steel at Elevated Temperatures," University of California Lawrence Livermore National Laboratory Report No. UCRL-ID-114590 (1993).

10. G. E. Dieter, Mechanical Metallurgy, Second Edition, McGraw-Hill, New York (1976). 
11. M. J. Manjoine, "Influence of Rate of Strain and Temperature on Yield Stresses of Mild Steel," J. Appl. Mech. 66, A221-A218 (1944).

12. C. G. Schmidt and A. K. Miller, "The Effect of Solutes on the Strength and Strain Hardening Behavior of Alloys," Acta Metall. 30, 615 (1982).

13. C. G. Schmidt and A. K. Miller, "A Unified Phenomenological Model for NonElastic Deformation of Type 316 Stainless Steel-Part II: Fitting and Predictive Capabilities," Res Mechanica 3, 175-193 (1981).

14. G. A. Henshall and A. K. Miller, "The Influence of Solutes on Flow Stress Plateaus, with Emphasis on Back Stresses and the Development of Unified Constitutive Equations," Acta Metall. 37, $2693-2704$ (1989).

15. B. A. Wilcox and A. R. Rosenfield, "On Serrated Yielding and Negative Strain-Rate Sensitivity," Mater. Sci. Engng. 1, $201-205$ (1966).

16. Metals Handbook, 9th ed., vol. 8, ASM International, Metals Park, OH (1984). 


\section{List of Figures}

1. The variation in the yield and ultimate tensile stresses with temperature for a variety of commercially pure vanadium materials. After Gold et al. [6].

2. The microstructure of the as-received vanadium sheet as a function of position within the sheet. The ASTM grain size number is given for various cross-sectional positions.

3. Schematic iliustration of the specimen geometry used to evaluate the tensile properties of commercially pure vanadium sheet. All dimensions are in $\mathrm{mm}$.

4. Geometry of the specimens used for testing the tensile properties of commercially pure vanadium rod. All dimensions are in $\mathrm{mm}$, except for the thread size which is given in inches.

5. The yield stress as a function of temperature for commercially pure vanadium sheet tested at a strain rate of $6.67 \times 10^{-4} \mathrm{~s}^{-1}$.

6. The ultimate tensile stress as a function of temperature for commercially pure vanadium sheet tested at a strain rate of $6.67 \times 10^{-4} \mathrm{~s}^{-1}$.

7. The elongation to failure as a function of temperature for commercially pure vanadium sheet tested at a strain rate of $6.67 \times 10^{-4} \mathrm{~s}^{-1}$.

8. The upper yield stress, lower yield stress, and ultimate tensile stress as a function of strain rate for commercially pure vanadium sheet tested at $20^{\circ} \mathrm{C}$.

9. The elongation to failure as a function of strain rate for commercially pure vanadium sheet tested at $20^{\circ} \mathrm{C}$.

10. The lower yield stress as a function of strain rate for commercially pure vanadium sheet tested at $20^{\circ} \mathrm{C}$, showing a strain-rate sensitivity of approximately 0.04 .

11. The temperature dependence of the yield stress for commercially pure vanadium sheet tested at a strain rate of $6.67 \times 10^{-2} \mathrm{~s}^{-1}$ is compared with that for material tested at a strain rate of $6.67 \times 10^{-4} \mathrm{~s}^{-1}$. 
12. The temperature dependence of the ultimate tensile stress for commercially pure vanadium sheet tested at a strain rate of $6.67 \times 10^{-2} \mathrm{~s}^{-1}$ is compared with that for material tested at a strain rate of $6.67 \times 10^{-4} \mathrm{~s}^{-1}$.

13. The temperature dependence of the elongation to failure for commercially pure vanadium sheet tested at a strain rate of $6.67 \times 10^{-2} \mathrm{~s}^{-1}$ is compared with that for material tested at a strain rate of $6.67 \times 10^{-4} \mathrm{~s}^{-1}$.

14. The temperature dependence of the yield stress for commercially pure vanadium rod tested at a strain rate of $6.67 \times 10^{-4} \mathrm{~s}^{-1}$ is compared with that for sheet material.

15. The temperature dependence of the ultimate tensile stress for commercially pure vanadium rod tested at a strain rate of $6.67 \times 10^{-4} \mathrm{~s}^{-1}$ is compared with that for sheet material.

16. The temperature dependence of thic elongation to failure for commercially pure vanadium rod tested at a strain rate of $6.67 \times 10^{-4} \mathrm{~s}^{-1}$ is compared with that for sheet material.

17. The temperature dependence of the ultimate tensile stress for commercially pure vanadium sheet from the present investigation is compared with that determined by dePruneda et al. [7]. 


\section{Appendix: Tabulated Data}

Table A.1 - Tensile properties of vanadium sheet deformed at an engineering strain rate of $6.67 \times 10^{-4} \mathrm{~s}^{-1}$.

\begin{tabular}{|c|c|c|c|c|c|c|c|c|c|}
\hline $\begin{array}{c}\text { Temperature } \\
\left({ }^{\circ} \mathrm{C}\right)\end{array}$ & $\begin{array}{l}\text { UYS } \\
\text { (ksi) }\end{array}$ & $\begin{array}{l}\text { LYS } \\
\text { (ksi) }\end{array}$ & $\begin{array}{l}0.2 \% \\
\text { Offset }\end{array}$ & $\begin{array}{l}\text { UTS } \\
\text { (ksi) }\end{array}$ & $\begin{array}{c}\text { Elongation } \\
(\%)\end{array}$ & $\begin{array}{l}\text { UYS } \\
\text { (MPa) }\end{array}$ & $\begin{array}{l}\text { LYS } \\
(\mathrm{MPa})\end{array}$ & $\begin{array}{l}0.2 \% \\
\text { Offset }\end{array}$ & $\begin{array}{l}\text { UTS } \\
\text { (MPa) }\end{array}$ \\
\hline $\begin{array}{l}20 \\
20 \\
20 \\
200 \\
400 \\
500 \\
500 \\
500 \\
600 \\
600 \\
650 \\
650 \\
700 \\
750 \\
800 \\
900 \\
900 \\
950 \\
1000 \\
1000 \\
1100 \\
1200\end{array}$ & $\begin{array}{l}31.100 \\
30.500 \\
34.200 \\
25.290 \\
29.860 \\
26.500 \\
30.000 \\
24.500 \\
22.570 \\
19.517 \\
18.750 \\
19.780 \\
19.746 \\
27.283 \\
18.700 \\
13.200 \\
15.500\end{array}$ & $\begin{array}{l}27.300 \\
30.500 \\
26.700 \\
20.710 \\
21.430 \\
18.900 \\
18.600 \\
18.700 \\
19.000 \\
17.955 \\
17.360 \\
18.790 \\
18.841 \\
18.043 \\
16.300 \\
11.900 \\
13.000\end{array}$ & $\begin{array}{r}10.543 \\
7.960 \\
9.279 \\
5.100 \\
1.640\end{array}$ & $\begin{array}{r}37.60)( \\
35.500 \\
36.200 \\
31.714 \\
33.290 \\
43.500 \\
41.500 \\
43.500 \\
33.860 \\
30.446 \\
27.960 \\
27.912 \\
24.728 \\
19.348 \\
17.400 \\
16.000 \\
15.500 \\
13.260 \\
9.270 \\
11.330 \\
5.500 \\
2.550\end{array}$ & $\begin{array}{r}54.0(0) \\
42.000 \\
54.500 \\
46.400 \\
39.700 \\
35.500 \\
37.500 \\
34.000 \\
59.700 \\
46.720 \\
53.600 \\
54.416 \\
62.914 \\
46.050 \\
52.174 \\
19.000 \\
22.000 \\
34.510 \\
77.000 \\
\\
82.400 \\
141.000 \\
\end{array}$ & $\begin{array}{r}214.435 \\
210.298 \\
235.809 \\
174.368 \\
205.877 \\
182.711 \\
206.843 \\
168.922 \\
155.620 \\
134.563 \\
129.280 \\
136.400 \\
136.147 \\
188.107 \\
128.932 \\
91.011 \\
106.869\end{array}$ & $\begin{array}{r}188.227 \\
210.290 \\
184.090 \\
142.790 \\
147.755 \\
130.311 \\
128.243 \\
128.932 \\
131.000 \\
123.798 \\
119.670 \\
129.600 \\
129.901 \\
124.405 \\
112.385 \\
82.048 \\
89.632\end{array}$ & $\begin{array}{l}72.695 \\
54.882 \\
63.975 \\
35.163 \\
11.307\end{array}$ & $\begin{array}{r}259.243 \\
244.764 \\
249.590 \\
218.633 \\
229.527 \\
299.922 \\
286.132 \\
299.922 \\
233.440 \\
209.919 \\
192.810 \\
192.447 \\
170.495 \\
133.399 \\
119.969 \\
110.316 \\
106.869 \\
91.431 \\
63.914 \\
78.124 \\
37.921 \\
17.582\end{array}$ \\
\hline
\end{tabular}


Table A.2 - Tensile properties of vanadium sheet deformed at an engineering strain rate of $6.67 \times 10^{-2} \mathrm{~s}^{-1}$.

\begin{tabular}{|c|c|c|c|c|c|c|c|}
\hline $\begin{array}{c}\text { Temperature } \\
\left({ }^{\circ} \mathrm{C}\right)\end{array}$ & $\begin{array}{c}\text { UYS } \\
(\mathrm{ksi})\end{array}$ & $\begin{array}{c}\text { LYS or } \\
0.2 \% \text { offset } \\
(\mathrm{ksi})\end{array}$ & $\begin{array}{c}\text { UTS } \\
(\mathrm{ksi})\end{array}$ & $\begin{array}{c}\text { Elongation } \\
(\%)\end{array}$ & $\begin{array}{c}\text { UYS } \\
(\mathrm{MPa})\end{array}$ & $\begin{array}{c}\text { LYS or } \\
0.2 \% \text { offset } \\
(\mathrm{MPa})\end{array}$ & $\begin{array}{c}\text { UTS } \\
(\mathrm{MPa})\end{array}$ \\
\hline 20 & 35.80 & 33.91 & 39.28 & 53.40 & 246.81 & 233.82 & 270.79 \\
20 & 37.32 & 34.78 & 40.94 & 58.24 & 257.31 & 239.80 & 282.27 \\
200 & 29.09 & 24.87 & 32.87 & 48.91 & 200.57 & 171.49 & 226.65 \\
400 & 29.27 & 22.90 & 32.17 & 42.62 & 201.85 & 157.88 & 221.83 \\
500 & 31.13 & 20.80 & 36.95 & 33.47 & 214.62 & 143.41 & 254.73 \\
550 & 19.42 & 18.99 & 36.23 & 34.02 & 133.90 & 130.90 & 249.81 \\
600 & 20.36 & 20.22 & 36.52 & 49.84 & 140.40 & 139.40 & 251.81 \\
800 & 17.10 & 16.80 & 19.57 & 73.50 & 117.80 & 115.80 & 134.90 \\
1000 & & 10.86 & 14.35 & 72.52 & & 74.88 & 98.92 \\
1000 & & 7.47 & 12.49 & 85.52 & & 51.50 & 86.12 \\
\hline
\end{tabular}

Table A.3 - Tensile properties of vanadium rod deformed at an engineering strain rate of $6.67 \times 10^{-4} \mathrm{~s}^{-1}$.

\begin{tabular}{|c|c|c|c|c|c|c|c|}
\hline $\begin{array}{c}\text { Temperature } \\
\left({ }^{\circ} \mathrm{C}\right)\end{array}$ & $\begin{array}{c}\text { LYS or } \\
0.2 \% \text { offset } \\
(\mathrm{ksi})\end{array}$ & UYS (ksi) & UTS (ksi) & $\begin{array}{c}\text { Elongation } \\
(\%)\end{array}$ & $\begin{array}{c}\text { LYS or } \\
0.2 \% \text { offset } \\
(\mathrm{MPa})\end{array}$ & $\begin{array}{c}\text { UYS } \\
(\mathrm{MPa})\end{array}$ & $\begin{array}{c}\text { UTS } \\
(\mathrm{MPa})\end{array}$ \\
\hline 20 & 22.170 & 29.860 & 32.460 & 63.700 & 152.862 & 205.885 & 223.812 \\
200 & 19.710 & 23.190 & 30.580 & 65.190 & 135.900 & 159.895 & 210.849 \\
500 & 15.040 & 24.280 & 41.670 & 48.070 & 103.701 & 167.411 & 287.315 \\
700 & 10.870 & & 32.750 & 66.420 & 74.949 & & 225.811 \\
700 & 10.200 & & 27.070 & 71.960 & 70.329 & & 186.648 \\
900 & 8.320 & & 13.260 & 74.300 & 57.366 & & 91.428 \\
1200 & 2.260 & & 3.420 & 96.000 & 15.583 & & 23.581 \\
\hline
\end{tabular}



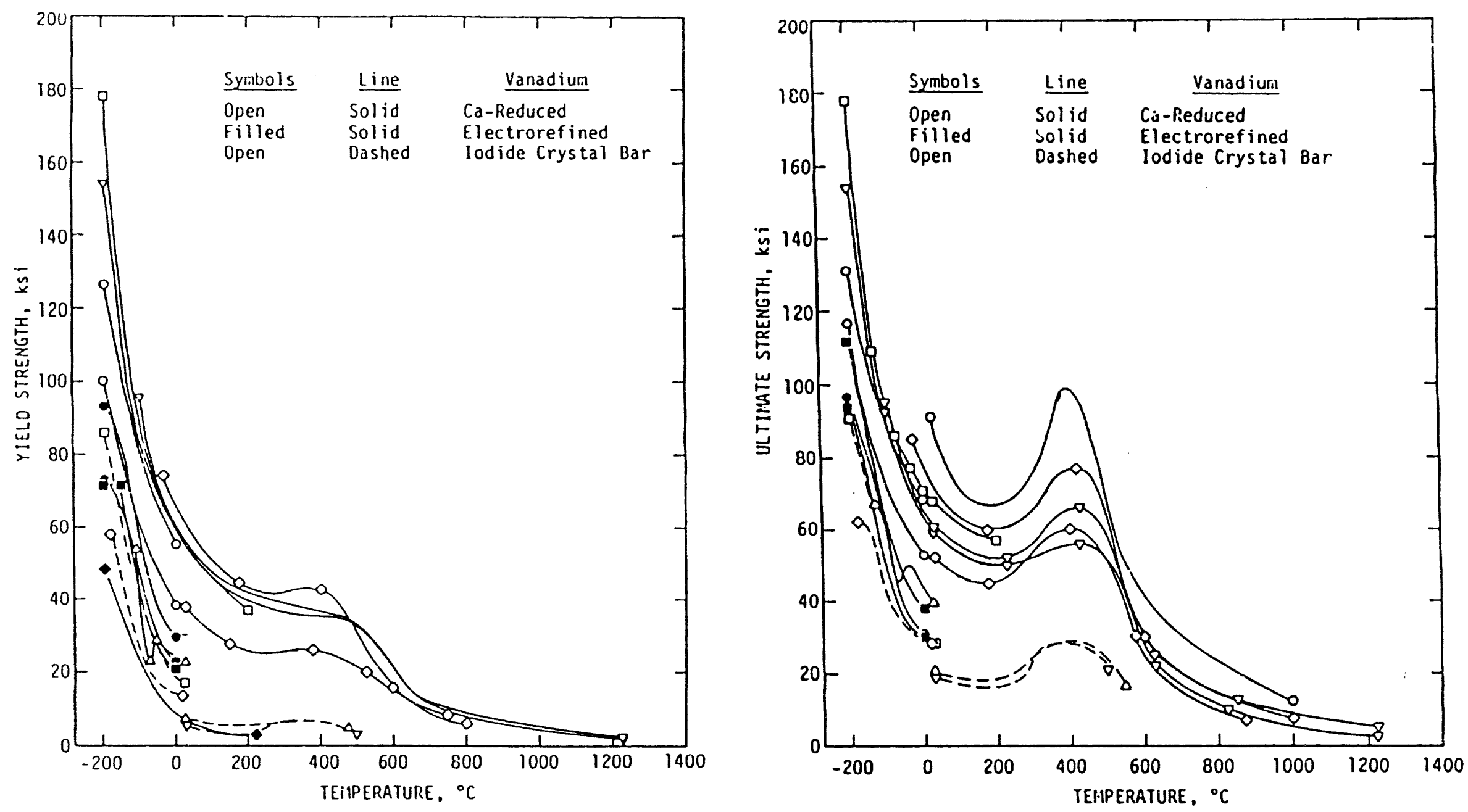

Figure 1. The variation in the yield and ultimate tensile stresses with temperature for a variety of commercially pure vanadium materials. After Gold et al. [6]. 


\section{Pure vanadium sheet (as received)}
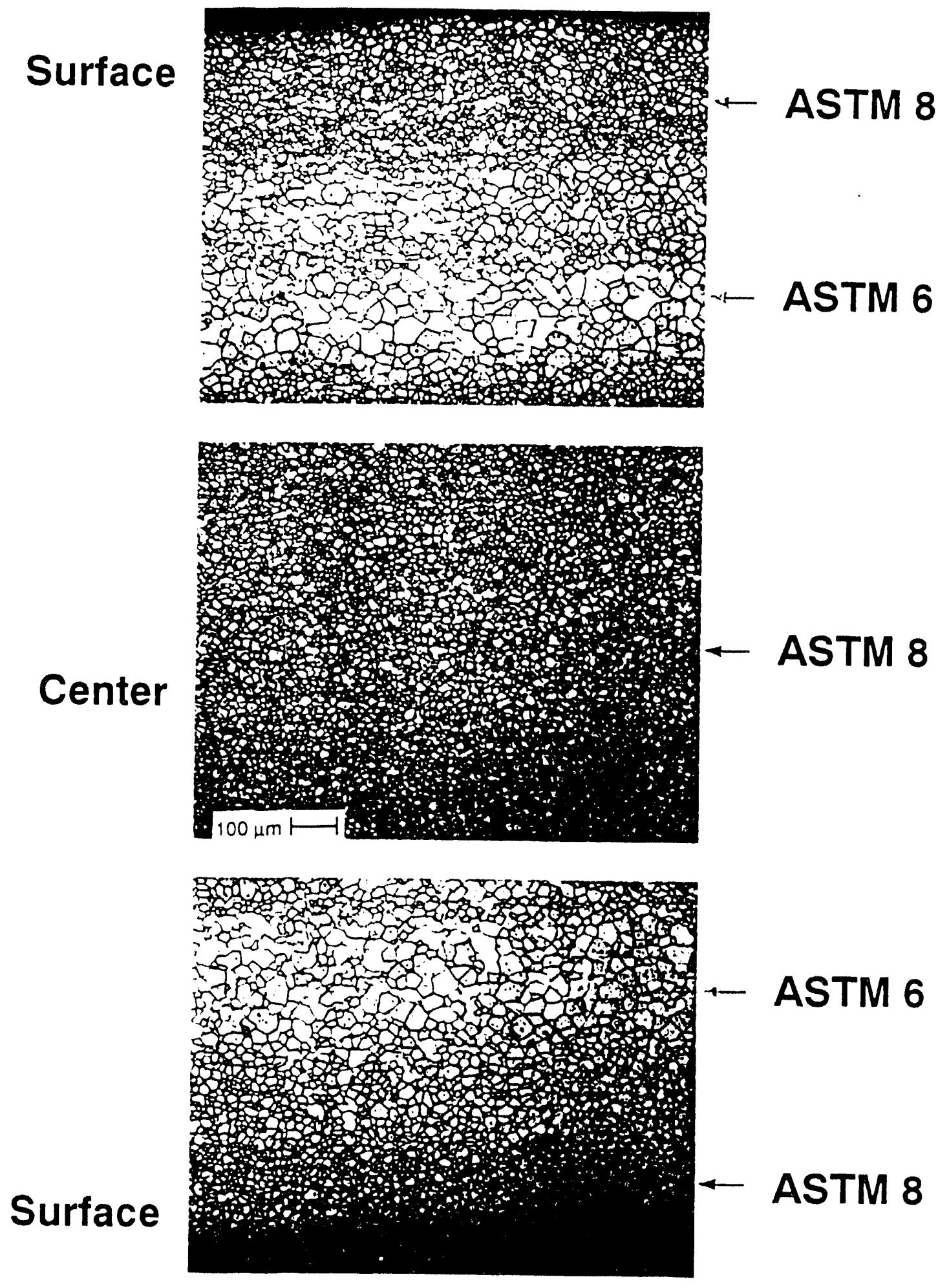

Figure 2. The microstructure of the as-received vanadium sheet as a function of position within the sheet. The ASTM grain size number is given for various cross-sectional positions. 


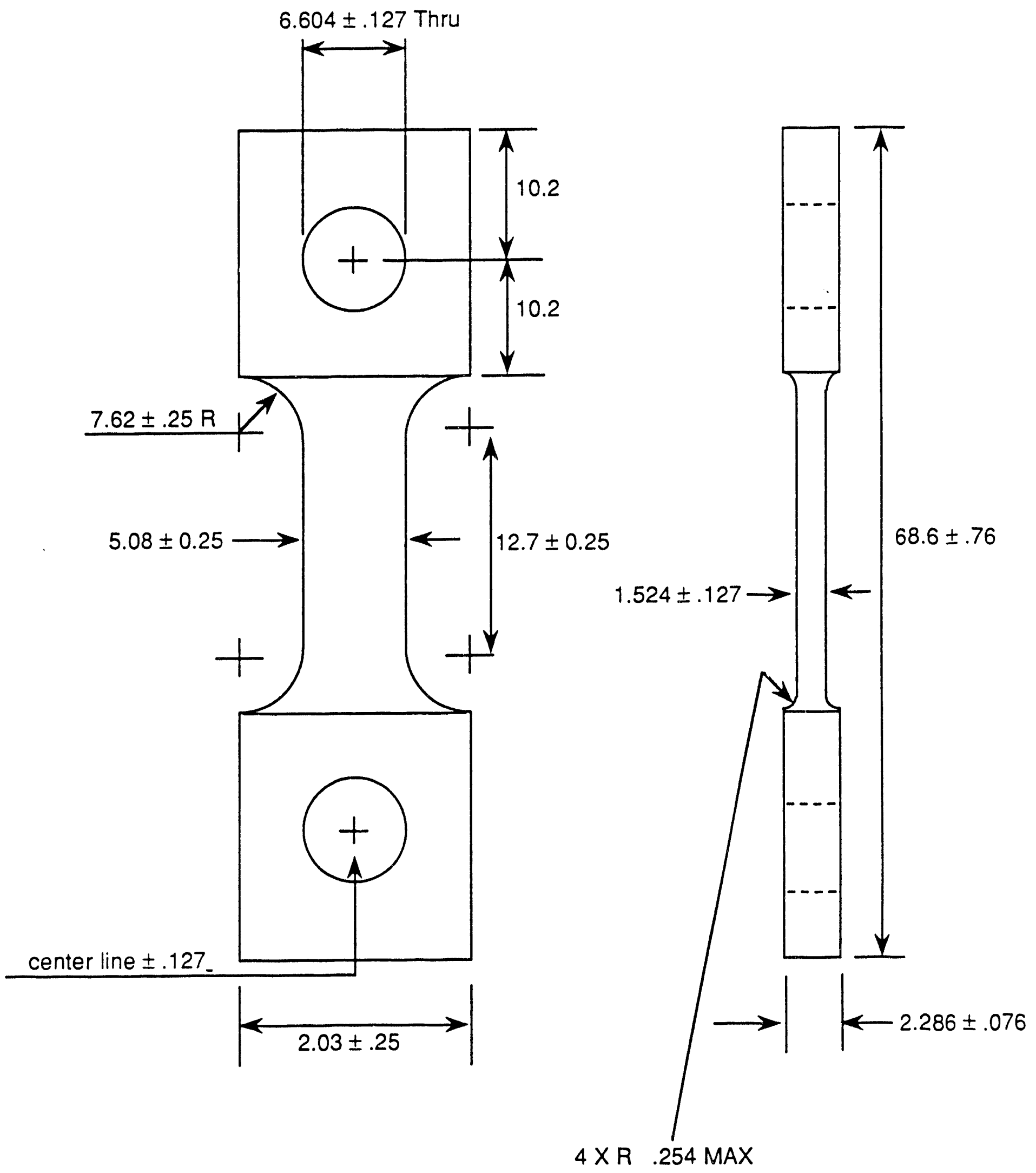

Figure 3. Schematic illustration of the specimen geometry used to evaluate the tensile properties of commercially pure vanadium sheet. All dimensions are in $\mathrm{mm}$. 


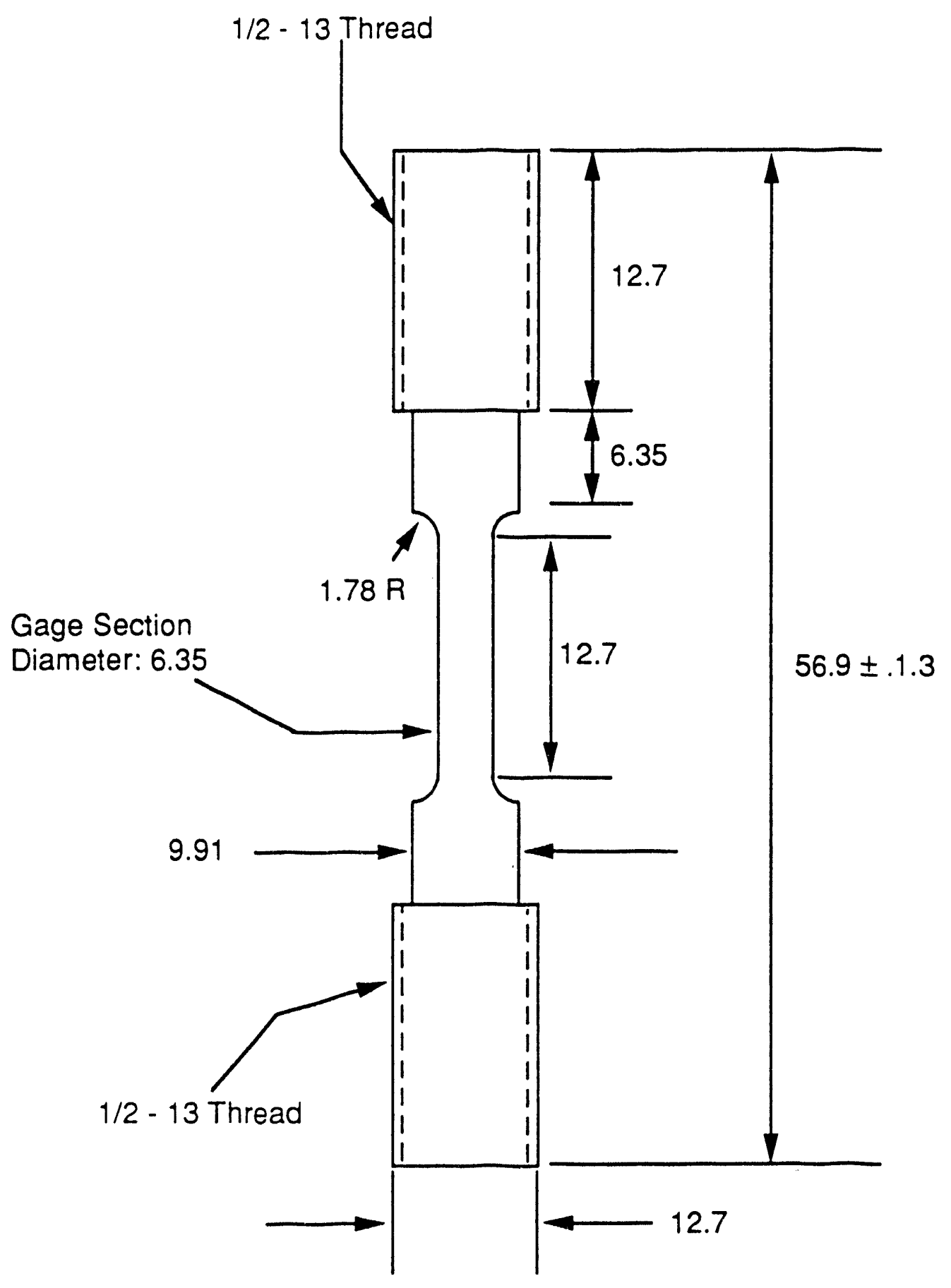

Figure 4. Geometry of the specimens used for testing the tensile properties of commercially pure vanadium rod. All dimensions are in $\mathrm{mm}$, except for the thread size which is given in inches. 


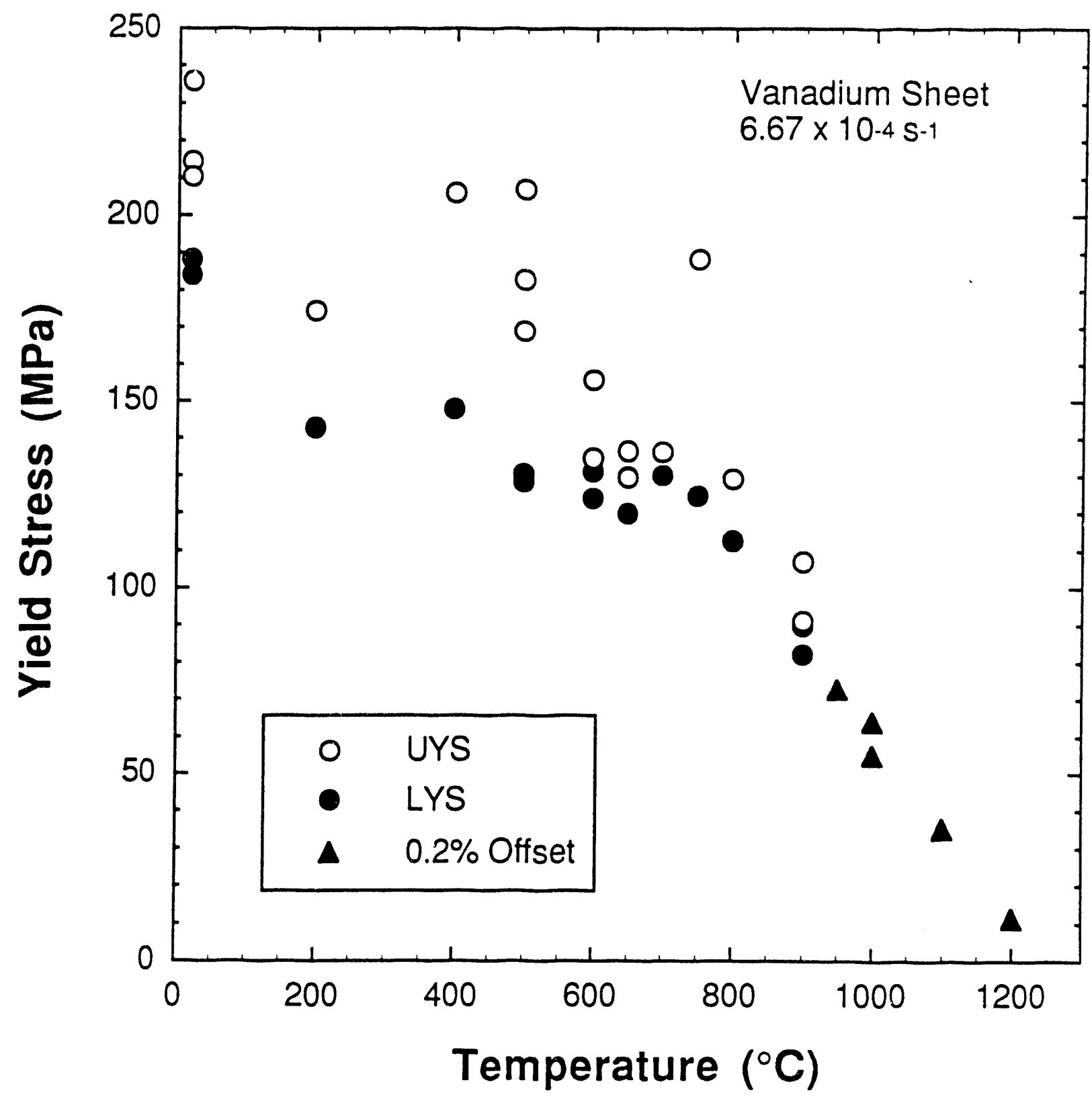

Figure 5. The yield stress as a function of temperature for commercially pure vanadium sheet tested at a strain rate of $6.67 \times 10^{-4} \mathrm{~s}-1$. 


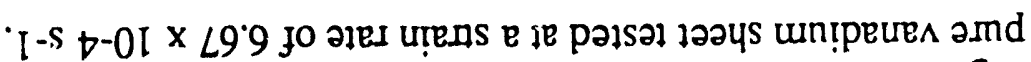

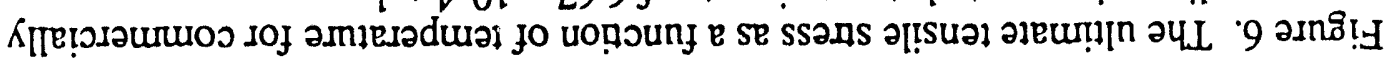

(0.) อגกłe.əduə।

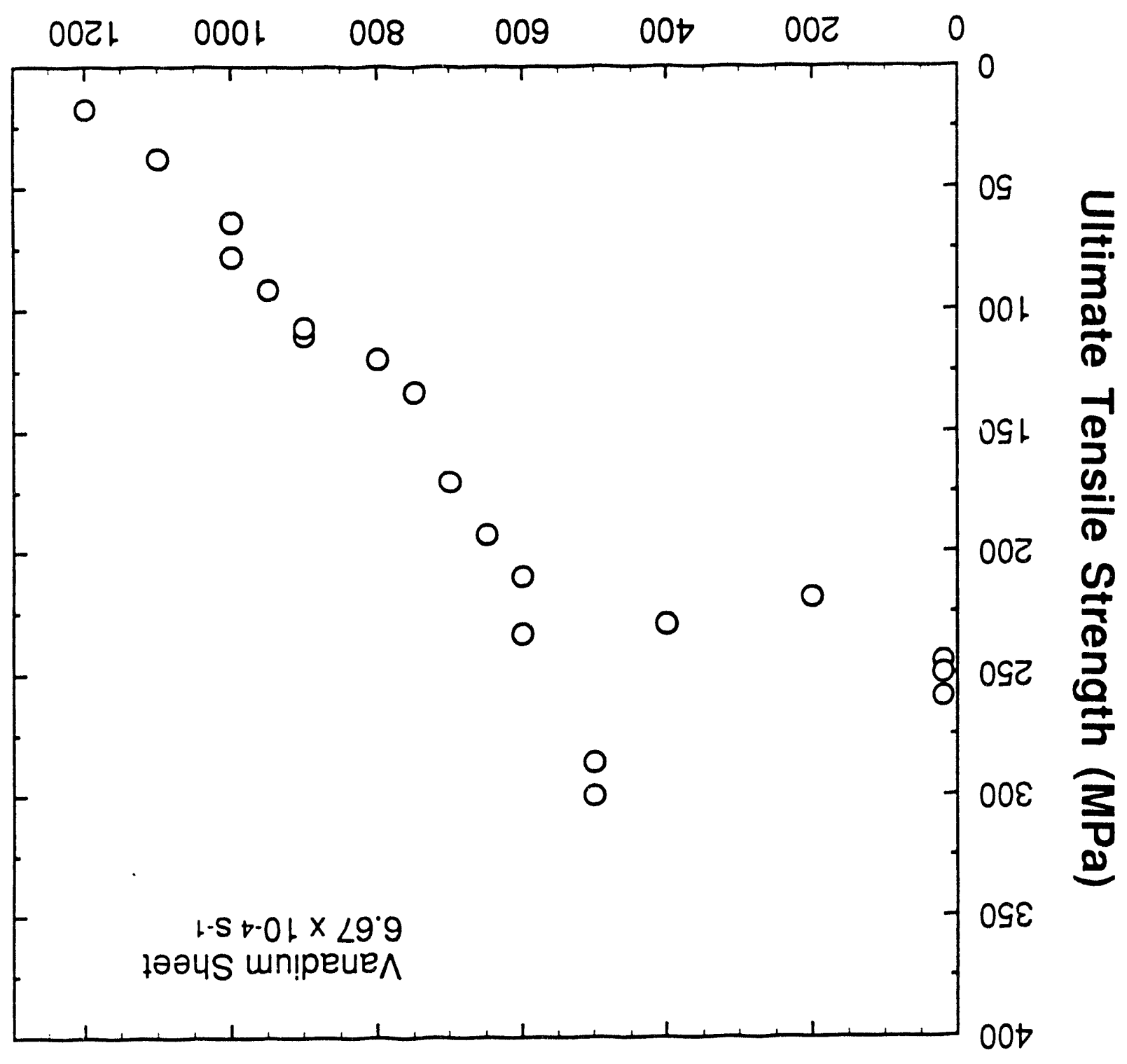




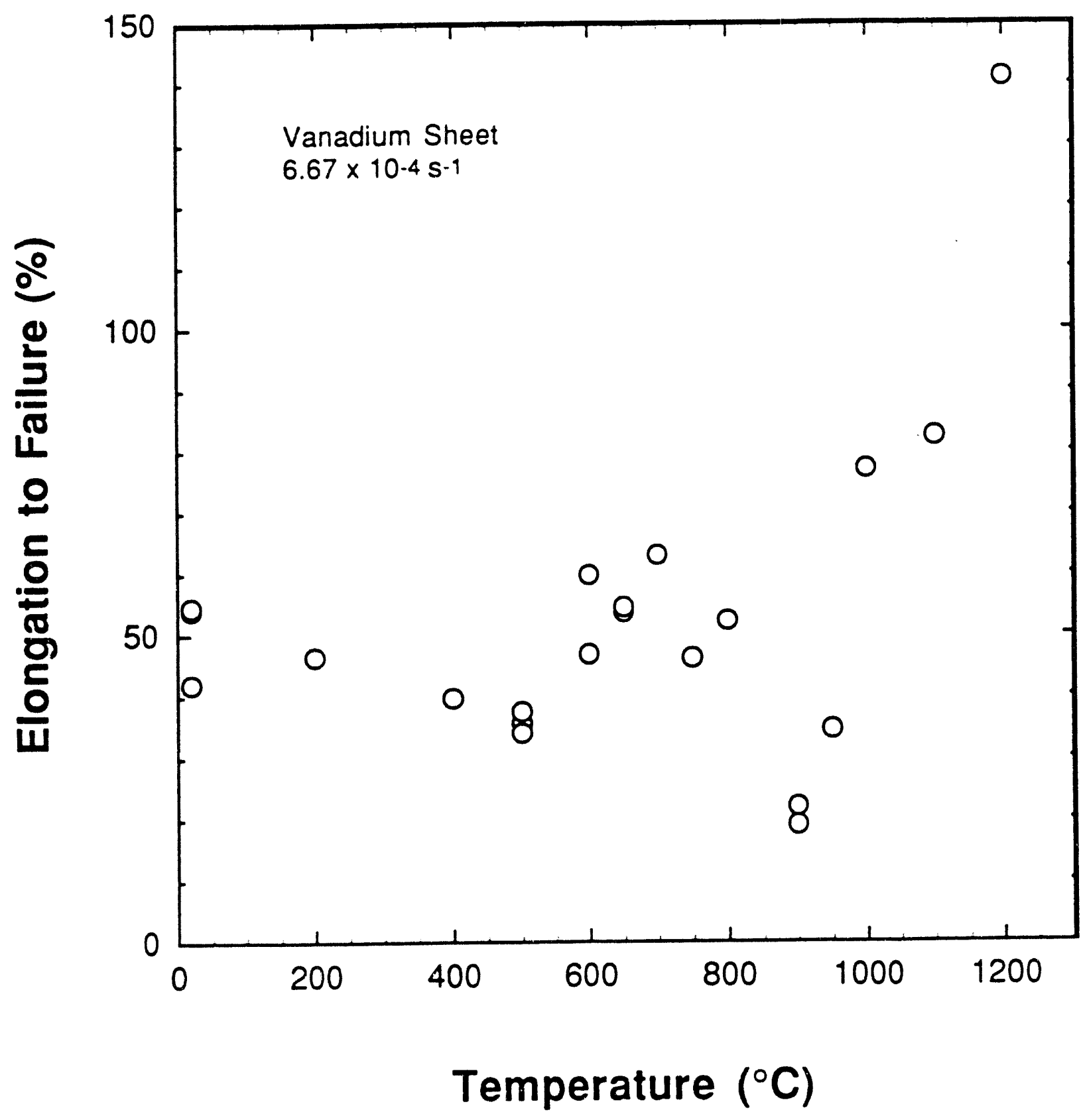

Figure 7. The elongation to failure as a function of temperature for commercially pure vanadium sheet tested at a strain rate of $6.67 \times 10^{-4} \mathrm{~s}-1$. 
כ. OZ le paisal jazys untpeures

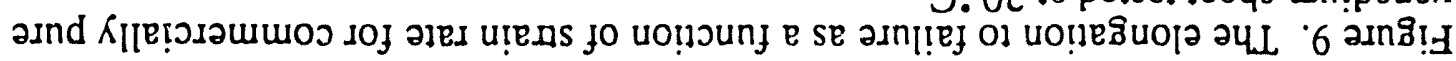

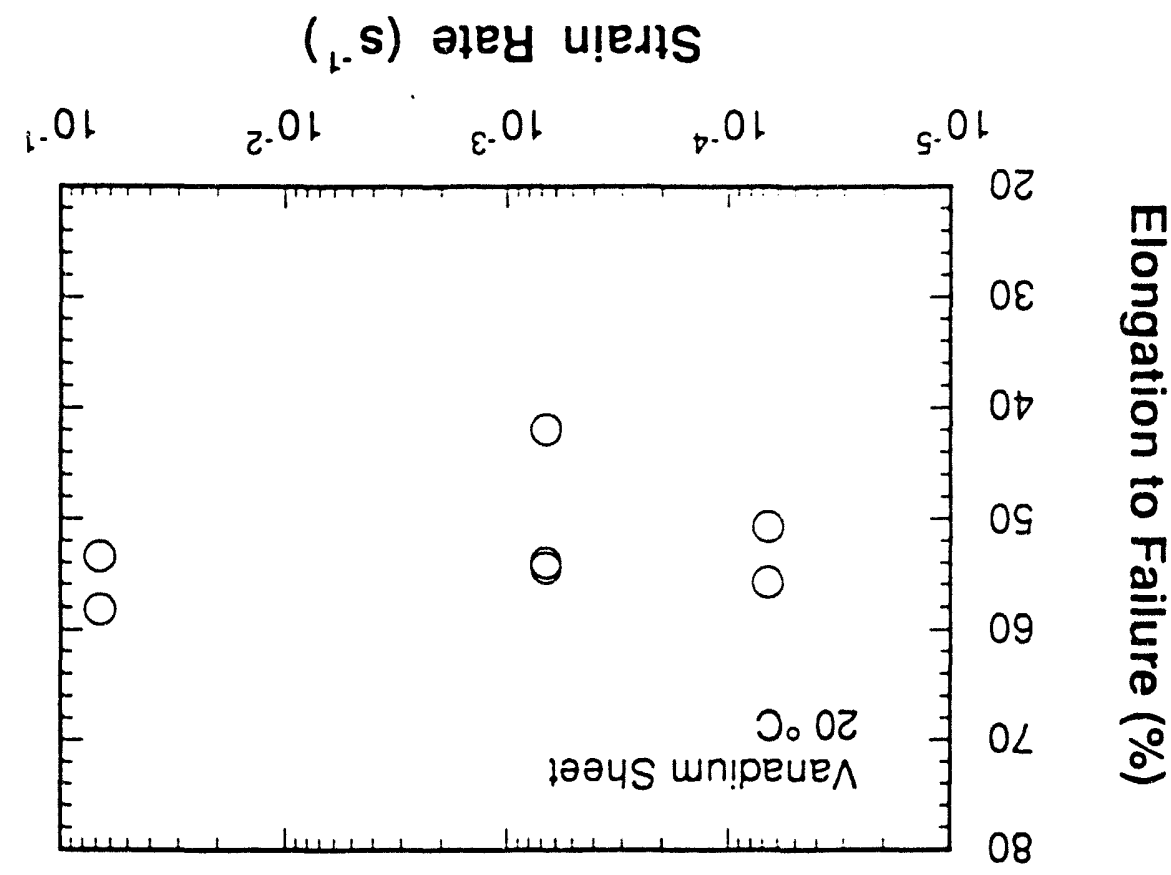

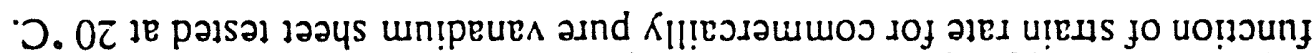

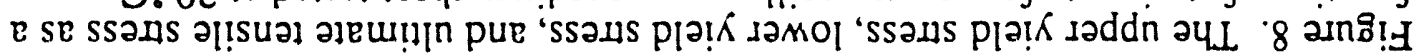

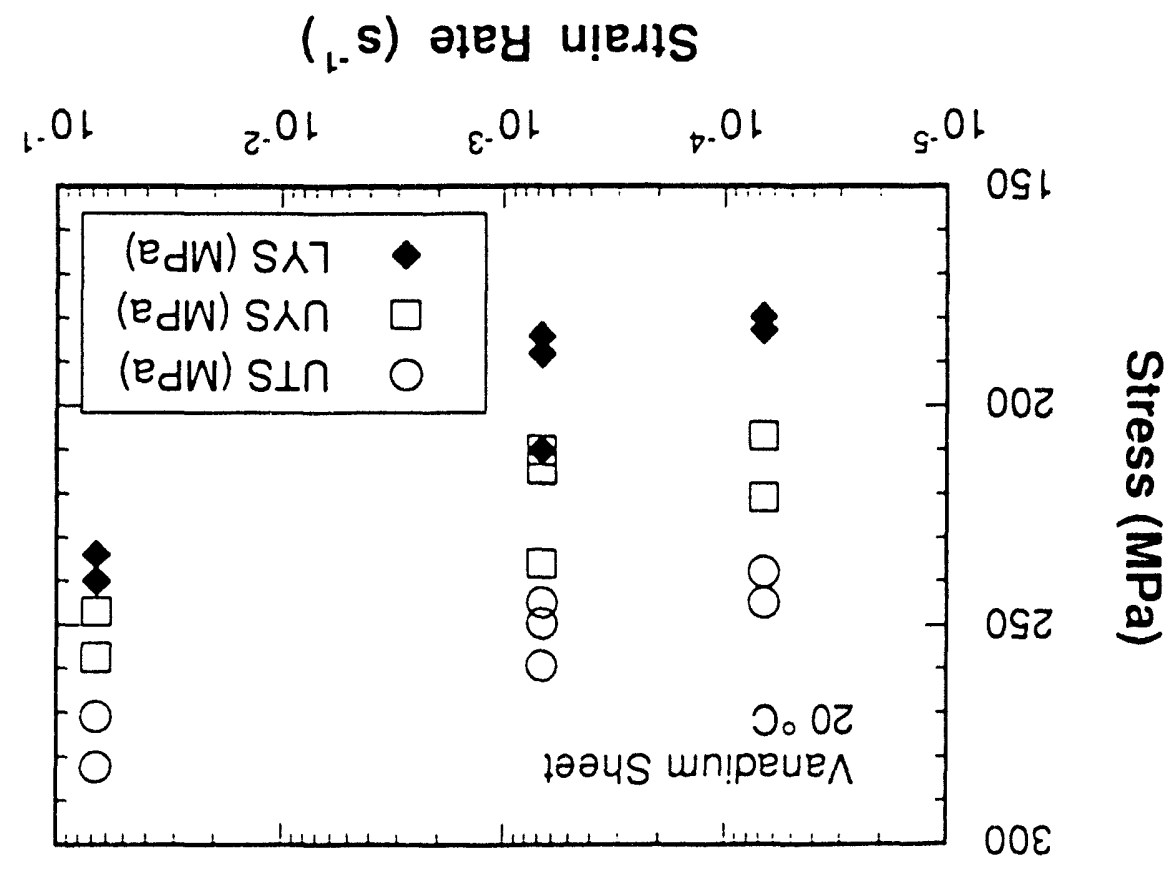




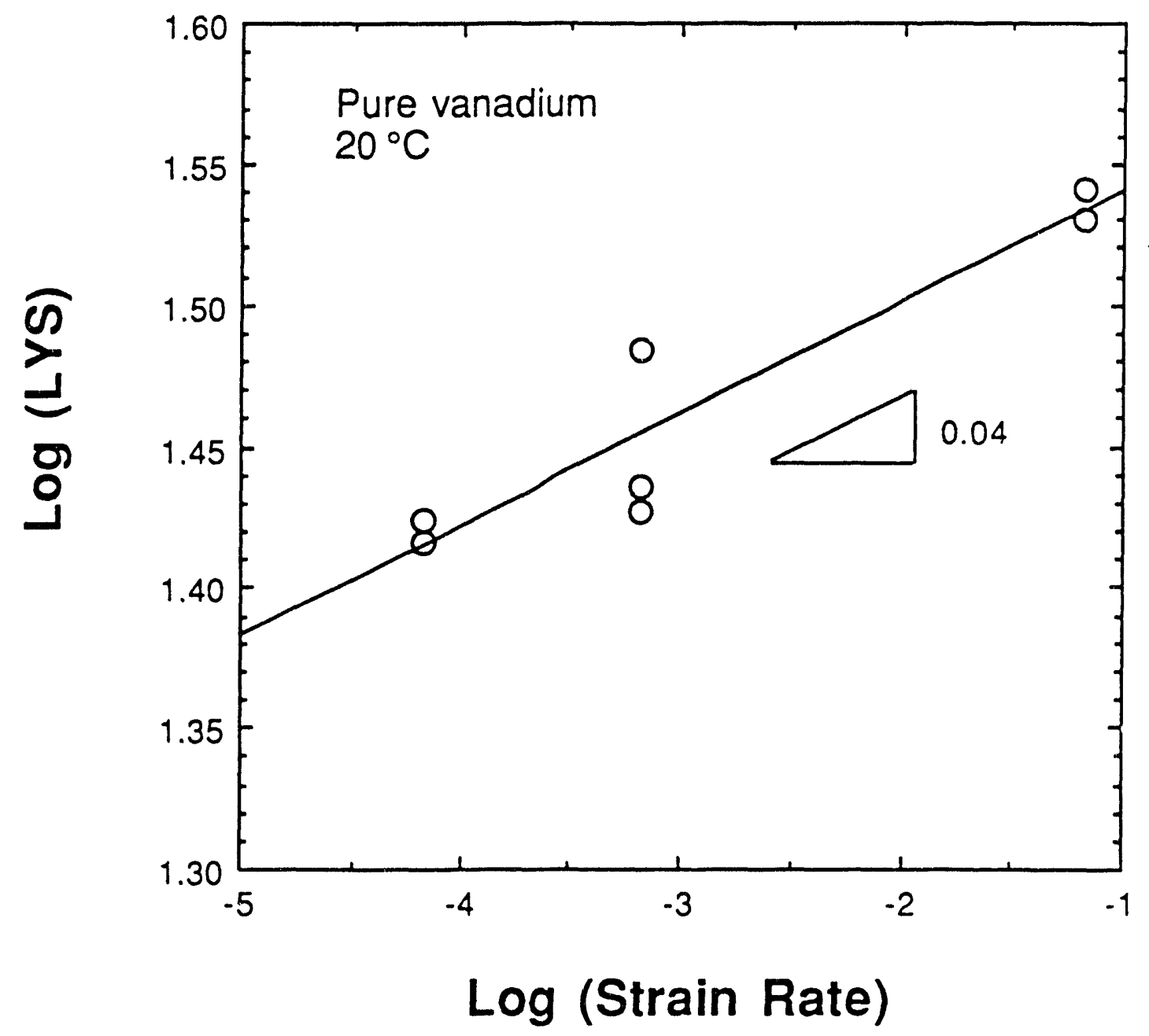

Figure 10. The lower yield stress as a function of strain rate for commercially pure vanadium sheet tested at $20^{\circ} \mathrm{C}$, showing a strain-rate sensitivity of approximately 0.04 . 


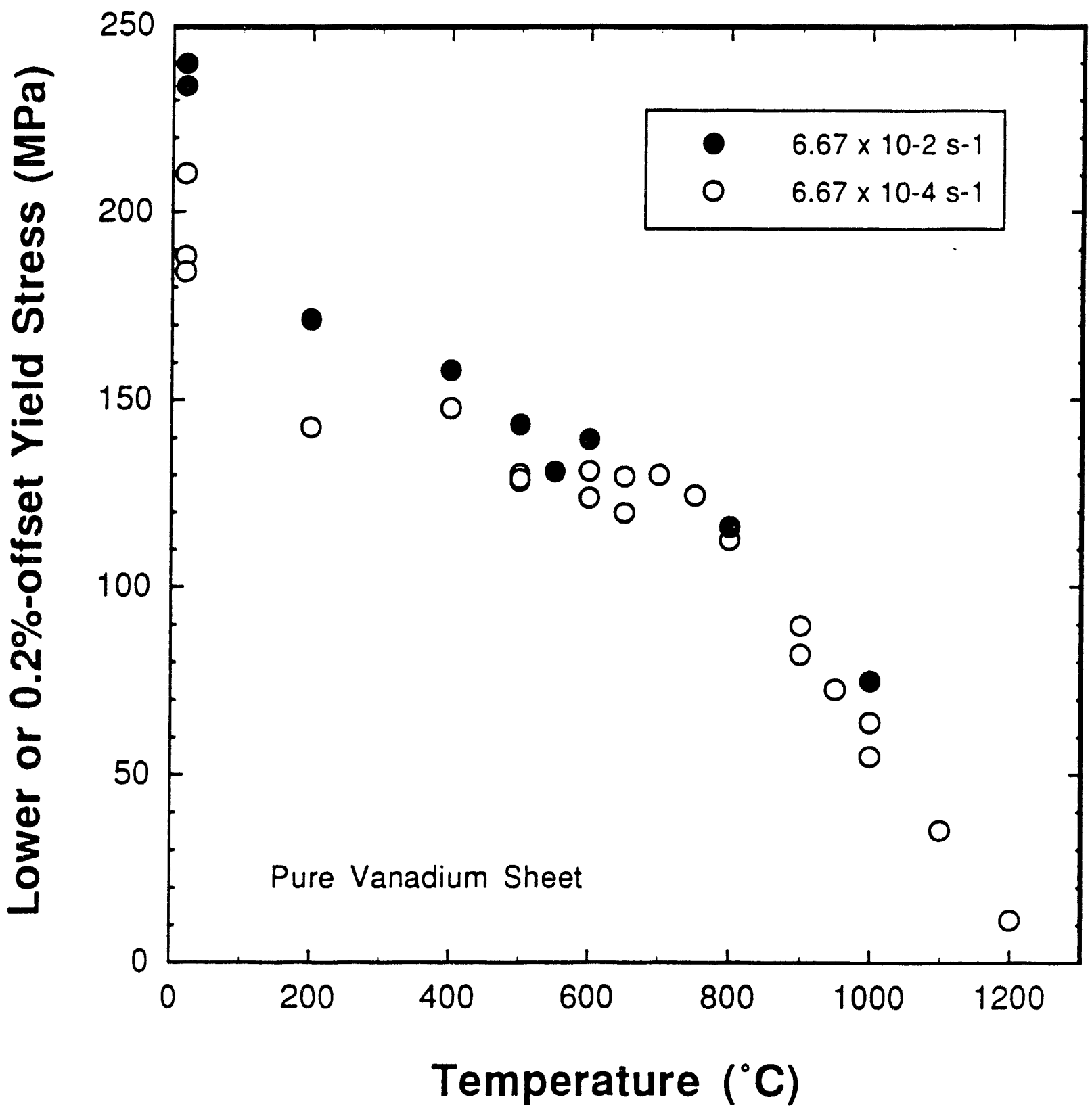

Figure 11. The temperature dependence of the yield stress for commercially pure vanadium sheet tested at a strain rate of $6.67 \times 10-2 \mathrm{~s}-1$ is compared with that for material tested at a strain rate of $6.67 \times 10^{-4} \mathrm{~s}-1$. 
i-S

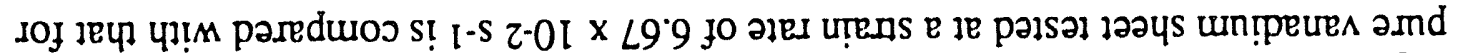

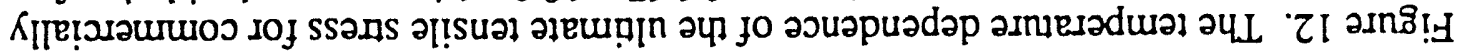

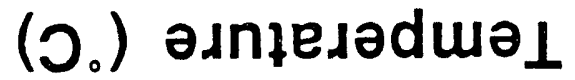

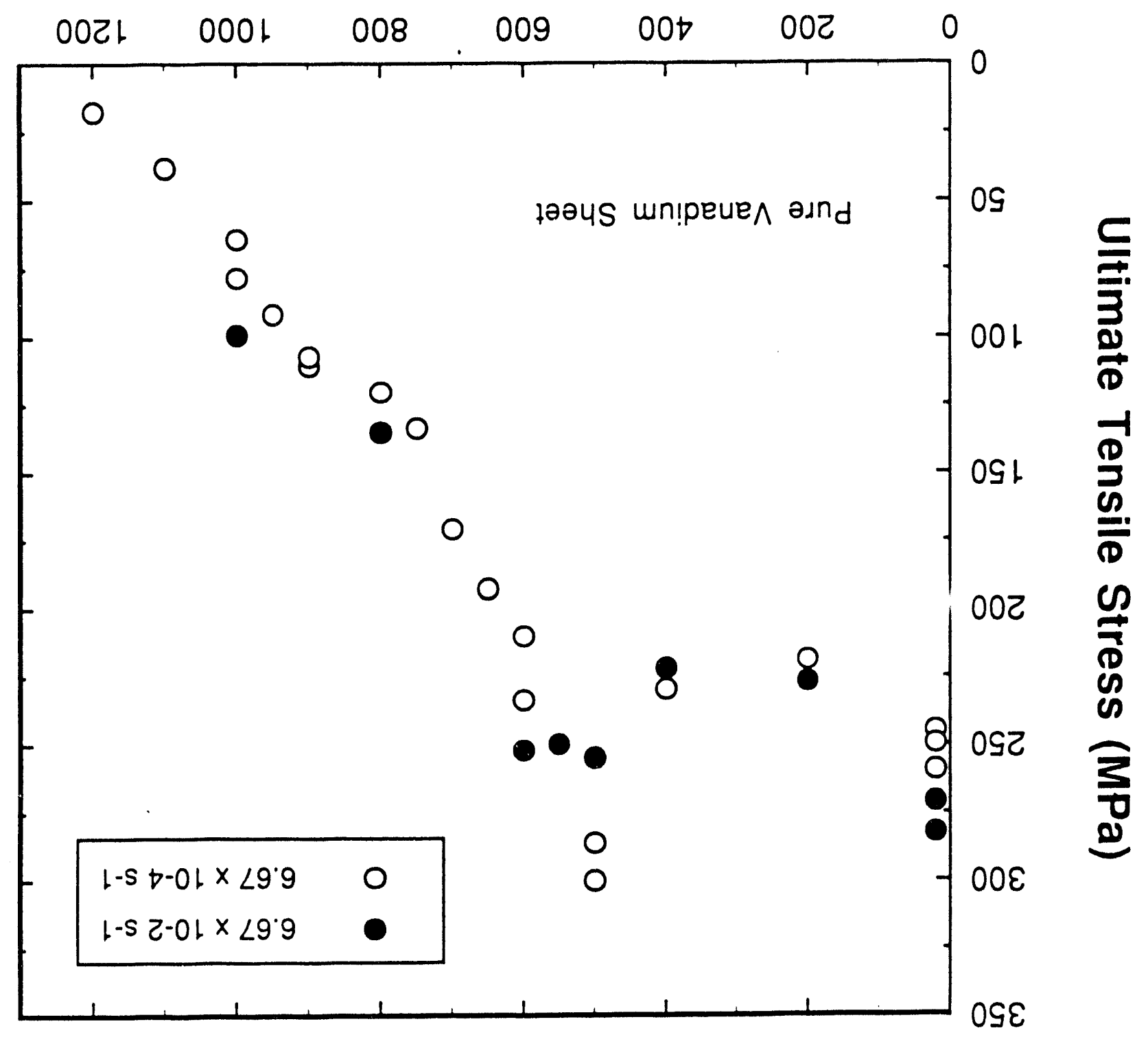




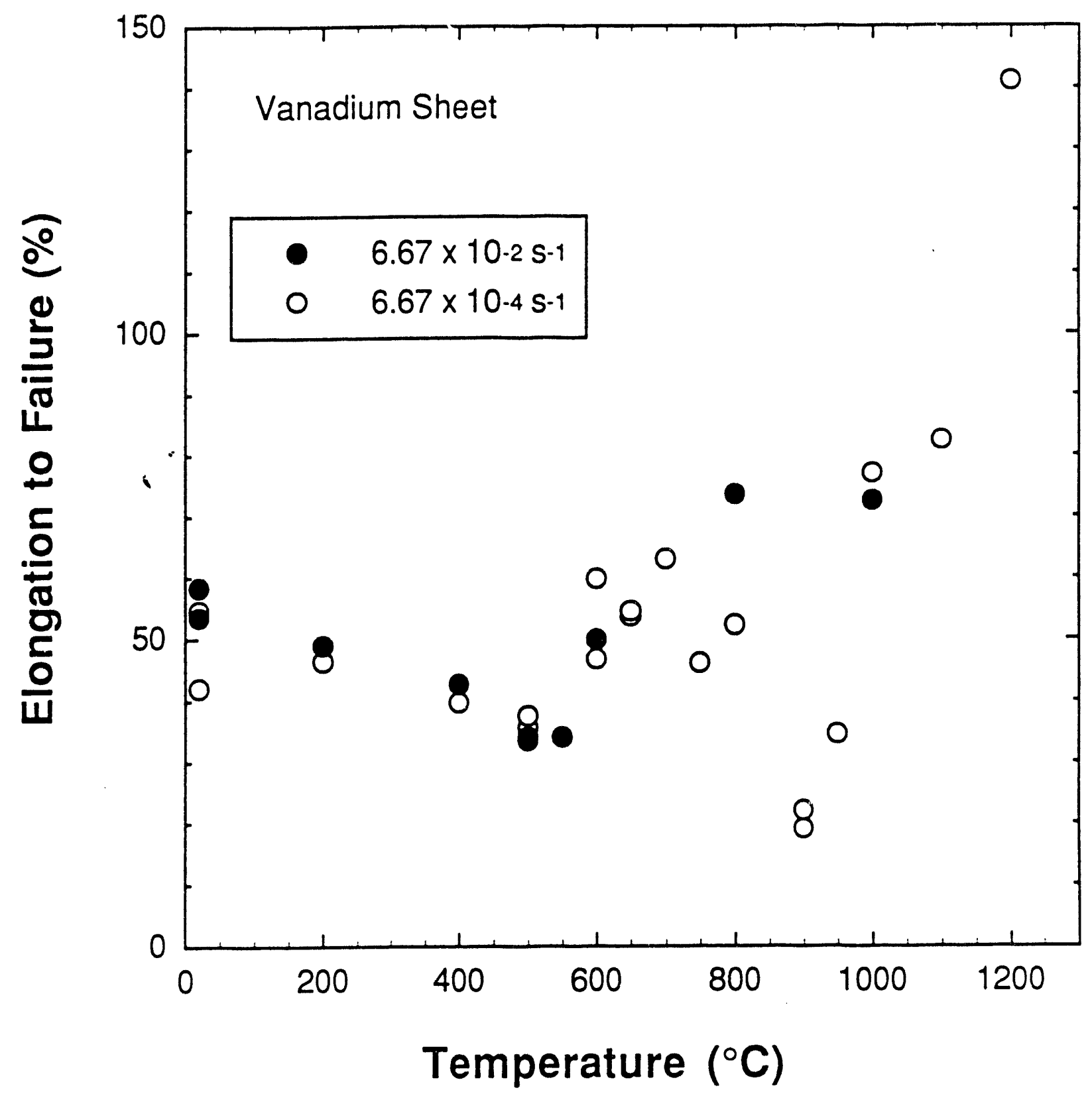

Figure 13. The temperature dependence of the elongation to failure for commercially pure vanadium sheet tested at a strain rate of $6.67 \times 10-2 \mathrm{~s}-1$ is compared with that for material tested at a strain rate of $6.67 \times 10^{-4} \mathrm{~s}-1$. 


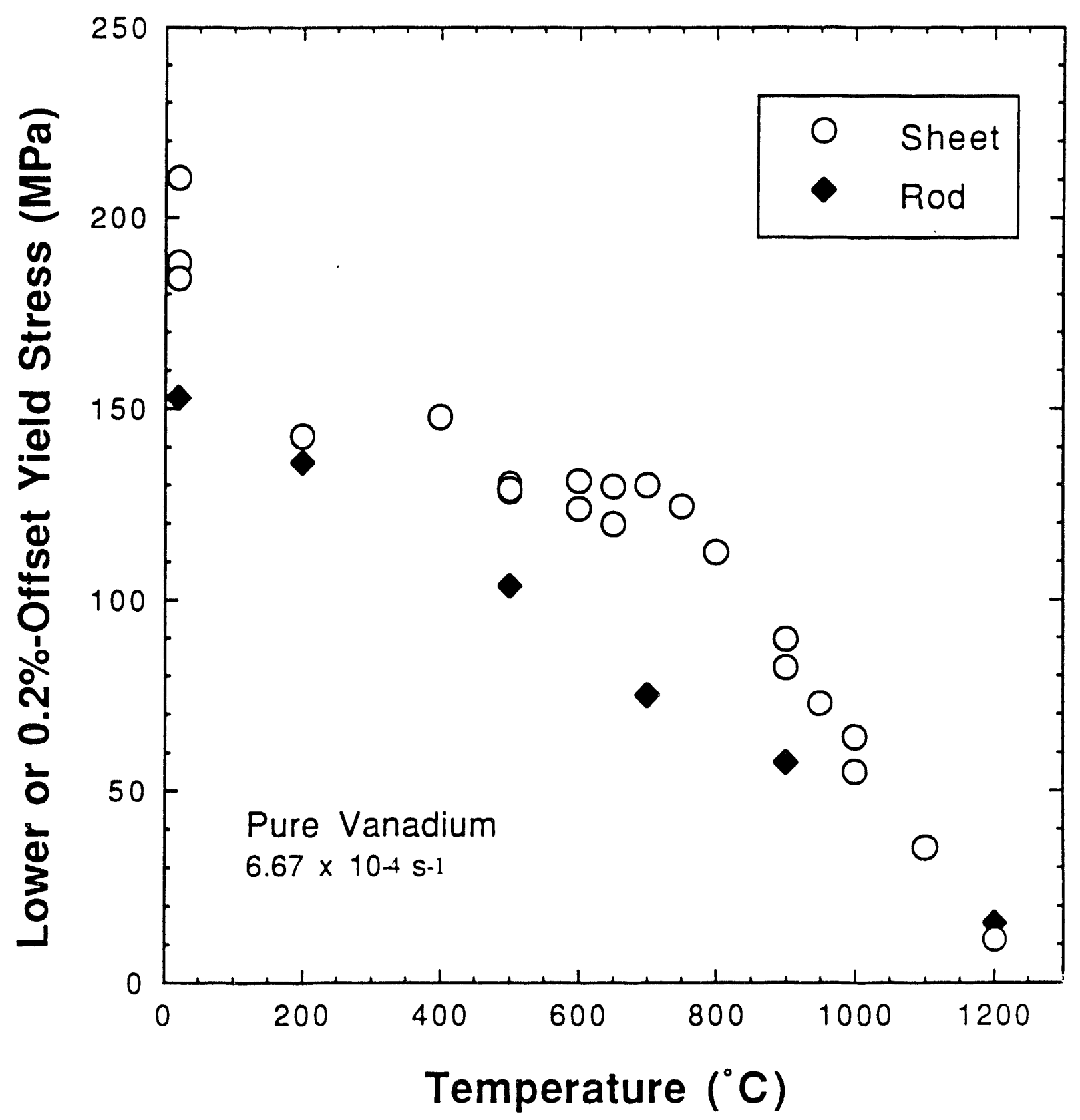

Figure 14. The temperature dependence of the yield stress for commercially pure vanadium rod tested at a strain rate of $6.67 \times 10^{-4} \mathrm{~s}^{-1}$ is compared with that for sheet material. 


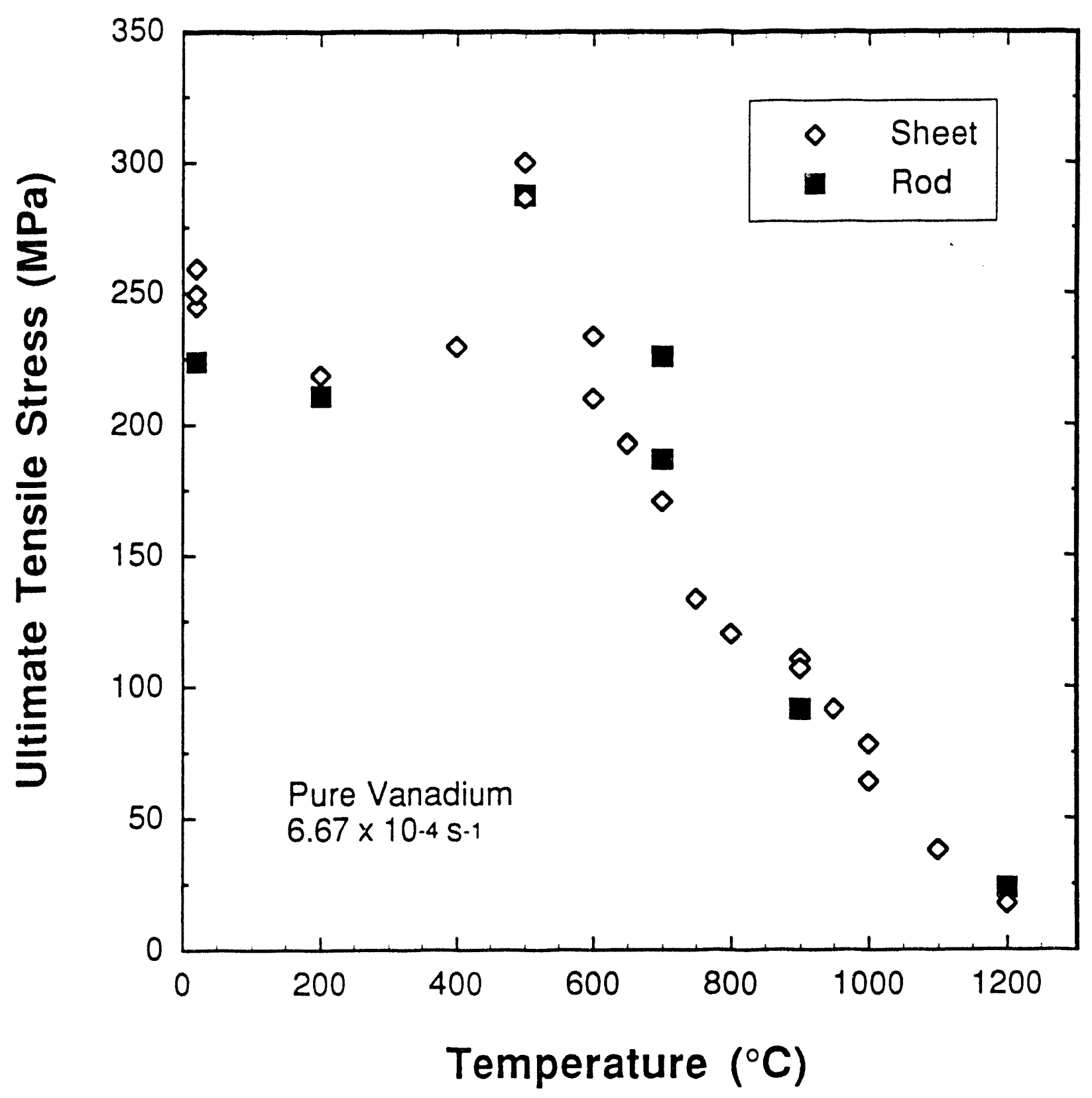

Figure 15. The temperature dependence of the ultimate tensile stress for commercially pure vanadium rod tested at a strain rate of $6.67 \times 10^{-4} \mathrm{~s}^{-1}$ is compared with that for sheet material. 


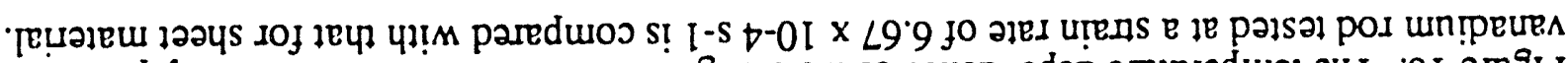

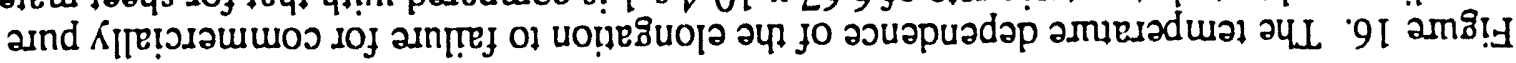

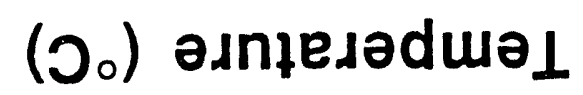

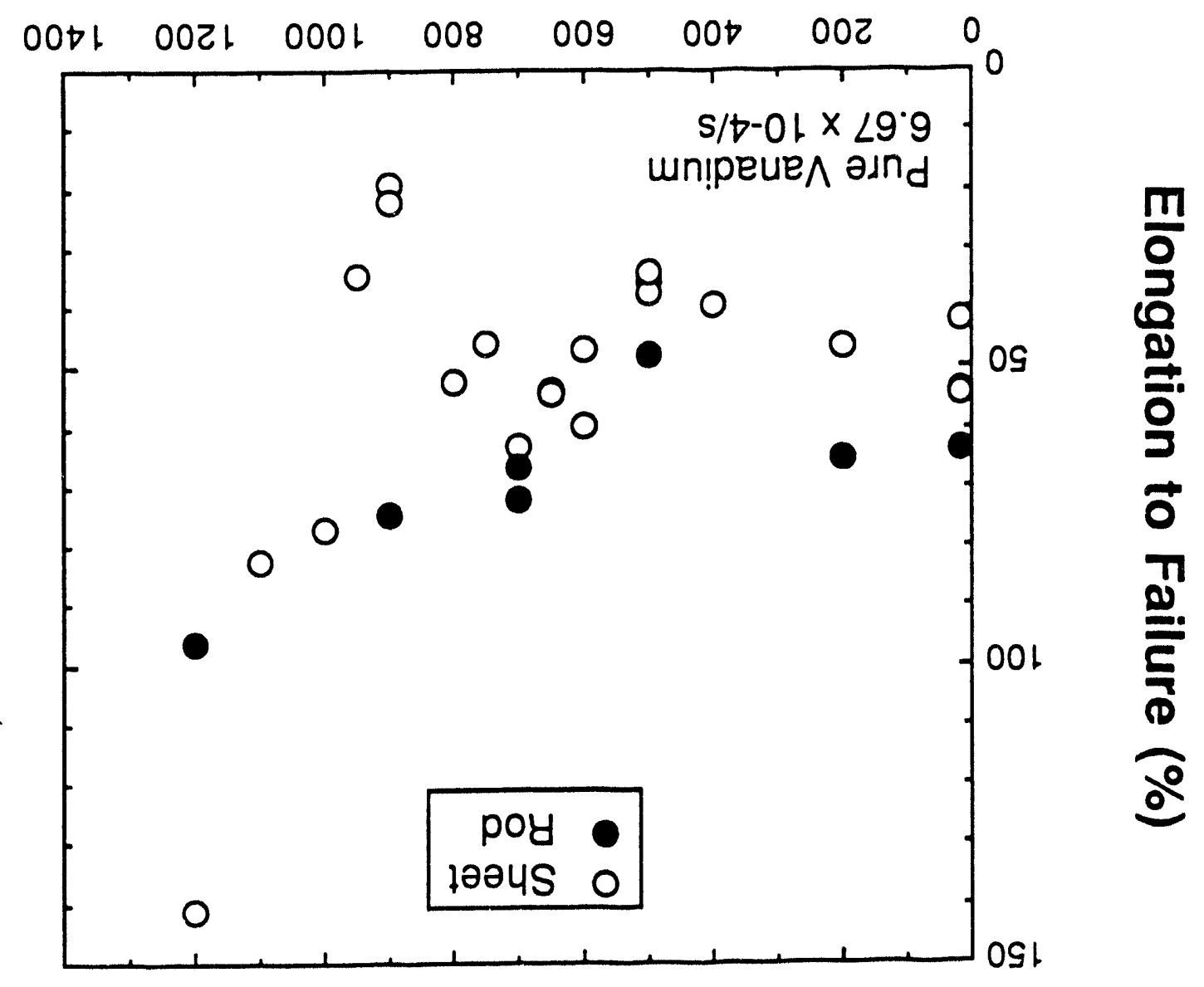




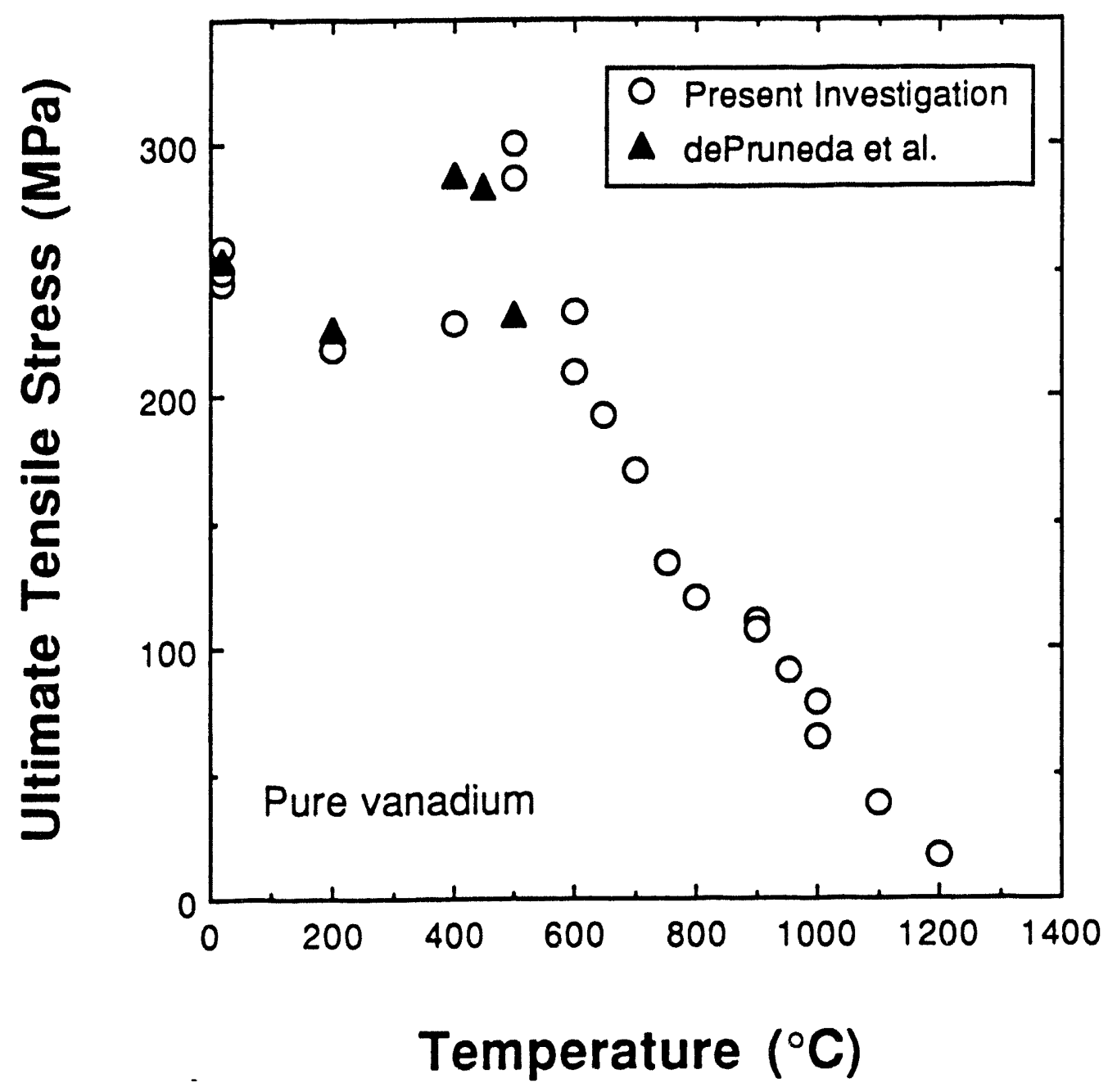

Figure 17. The temperature dependence of the ultimate tensile stress for commercially pure vanadium sheet from the present investigation is compared with that by dePruneda et al. [7]. 

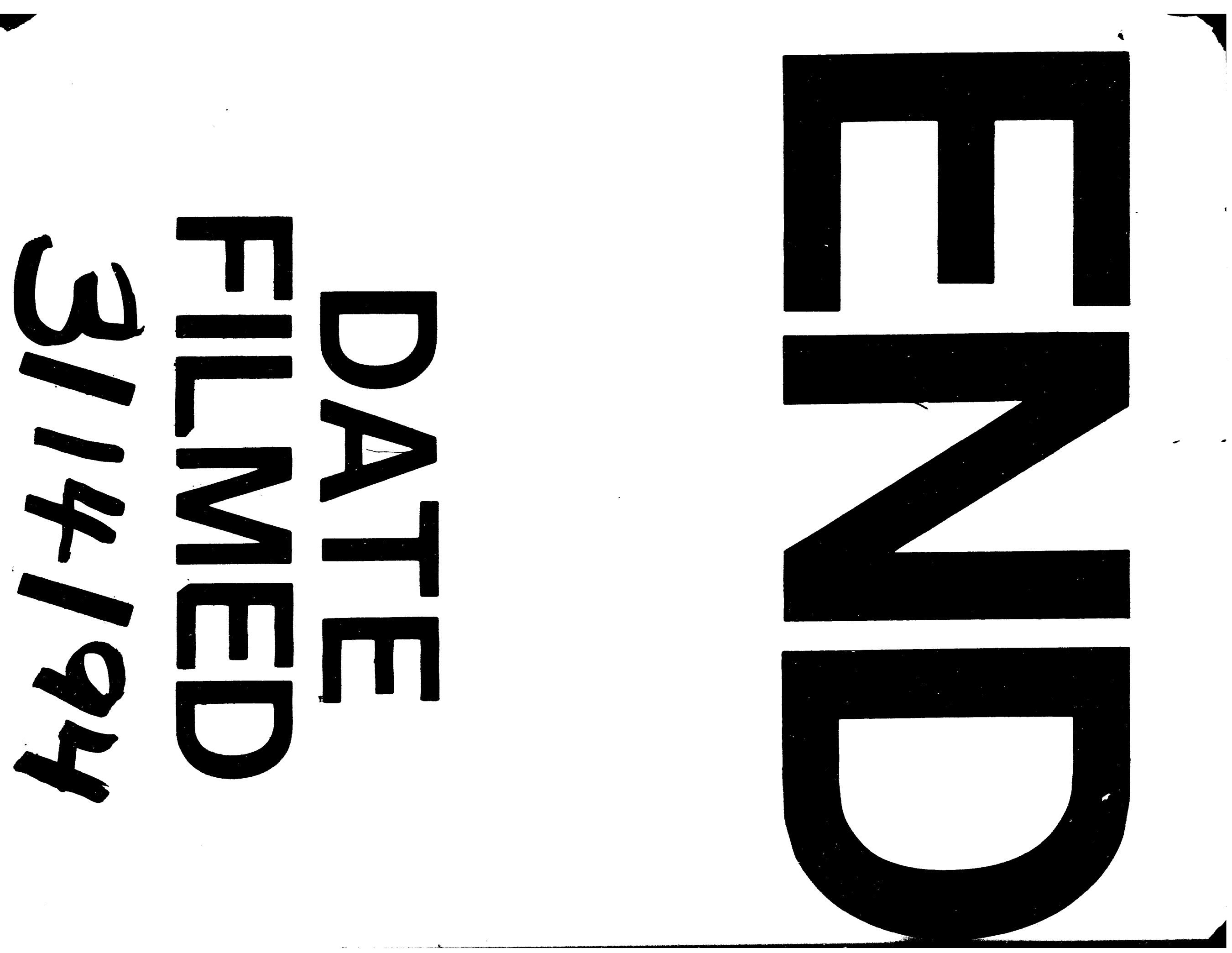
